
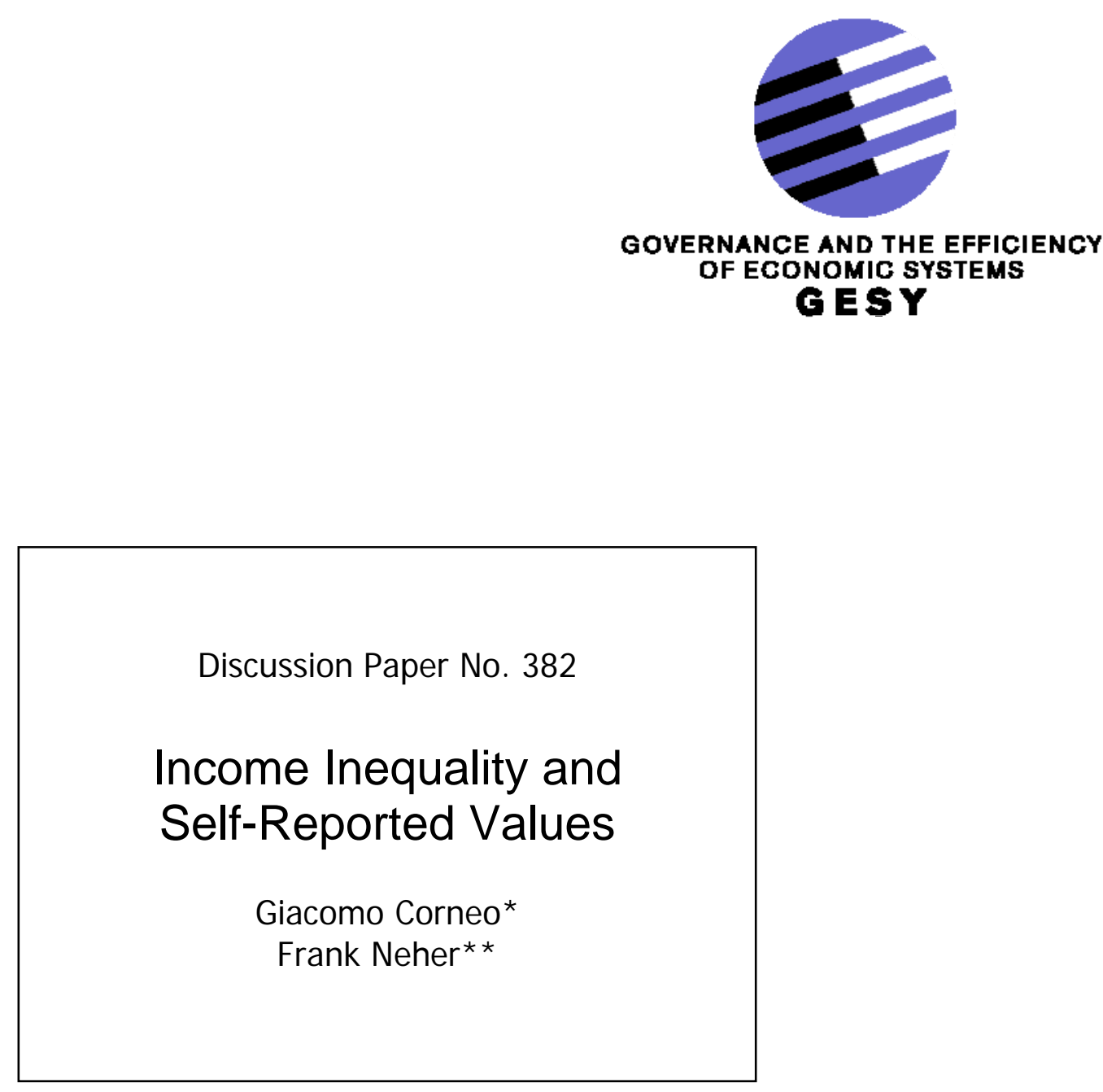

* Free University of Berlin

** Free University of Berlin

May 2012

Financial support from the Deutsche Forschungsgemeinschaft through SFB/TR 15 is gratefully acknowledged. 


\title{
Income Inequality and Self-Reported Values
}

\author{
Giacomo Corneo* and Frank Neher**
}

May 2012

Abstract: $\quad$ This paper offers a comprehensive econometric investigation of the impact of income inequality on the values endorsed by people. Using survey data from all thirty-four OECD countries over a period of almost thirty years, the following dimensions of value systems are investigated: work ethic, civism, obedience, honesty, altruism, and tolerance. In most cases, no robust effects from inequality on values are detected. However, there is evidence that a more unequal income distribution strengthens the work ethic of the population. Thus, income inequality seems to generate work incentives not only via the pecuniary reward of work but also through the symbolic reward it receives.

Keywords: Income inequality, Value systems.

JEL-Classification: D63, O15, O57, Z1

* Affiliations: Free University of Berlin, CEPR London, CESifo Munich, IZA Bonn. Email address: giacomo.corneo@fu-berlin.de. ** Affiliation: Free University of Berlin. Email address: frank.neher@fu-berlin.de.

Acknowledgements: This paper combines parts of previous unpublished work by the authors (Corneo, 2011; Neher, 2012) and substantially extends it. The paper has benefitted from helpful suggestions by participants in workshops of the GINI Project in Amsterdam and London, where some of its results were presented. The current version has benefitted from helpful comments by Wilfried Altzinger and Paolo Vanin. Financial support from the Deutsche Forschungsgemeinschaft through SFB/TR 15 is gratefully acknowledged. 


\section{Introduction}

A strand of empirical literature has documented the association of income inequality with a number of outcomes, including well-being, health, trust, and crime - often arguing that income inequality causes those outcomes to worsen. ${ }^{1}$ Income inequality may affect outcomes through two main channels. First, the distribution of income determines the budget sets faced by households and hence the range of options and outcomes that are available to them. Second, the effect from inequality may be mediated by various forms of cultural change. In particular, income inequality may shape the values and norms endorsed by people, which in turn influence their behavior. This paper explores the link between income inequality and self-reported values. It shows that that relationship differs according to the specific values one considers: income inequality cannot significantly explain the observed variation in endorsed values in several cases, but there are exceptions where inequality matters.

Being self-reliant, always telling the truth, and donating to the needy are examples of behavior that carries a symbolic value: self-respect and the respect gained from others depend on those ways of behaving. But this does not apply to everybody to the same extent because people endorse different values. Psychology, anthropology and sociology have since long investigated the variability of values and norms - both within and across societies. For example, Inglehart and Baker (2000) recently argued that developed countries after World War II experienced a transition from "traditional” to “modern” values.

Values affect people's choices and welfare through an individual and a social channel. The individual channel is the unpleasant feeling of guilt that one has if one's behavior violates one's own moral standards and the symmetric pride if one behaves in line with internalized values. The social channel refers to the esteem received from relevant others - family, colleagues, neighbors, etc. - which in turn depends on those others' value systems: one gains approval by conforming to others' values, while contempt is received if one's behavior contradicts them. As stressed by a burgeoning literature in economics, values can contribute to explain a wide range of economic phenomena, from long-run growth to occupational choice, from the internal organization of firms to labor market institutions. ${ }^{2}$ In view of the recent rise of income inequality in many parts of the world, understanding the impact of inequality on values may thus help to better predict those phenomena. ${ }^{3}$

\footnotetext{
${ }^{1}$ Wilkinson and Pickett (2009) offer a stimulating overview.

${ }^{2}$ See e.g. Algan and Cahuc (2009), Auriol and Renault (2008), Corneo and Jeanne (2010), Doepke and Zilibotti (2008) and Tabellini (2008), as well as the discussion by Fehr and Hoff (2011).

${ }^{3}$ Recent trends of income inequality are documented in a cross-country perspective in OECD (2008, 2011). On global inequality, see Milanovic (2012).
} 
This paper systematically explores multi-country data on self-reported values over a time horizon of almost three decades and relates value change to changes in income inequality. The following six dimensions of value systems are investigated: work ethic, civism, obedience, honesty, altruism, and tolerance. Each of those dimensions is likely to generate incentive effects in important areas of economic, social, and political behavior. For instance, work ethic is bound to affect households' labor supply, while civism is a likely determinant of tax compliance.

In the next section, we develop a simple theoretical framework that exhibits a channel through which income inequality can affect value formation in a causal sense. That framework is based on the hypothesis of purposive value formation, a hypothesis pioneered in economics by Akerlof (1983). The particular approach we follow is the one developed by Corneo and Jeanne (2009, 2010). An individual's value system is defined as a mapping that determines an individual's self-esteem and how she judge others; parents are assumed to choose value systems so as to maximize their children's expected utility. ${ }^{4}$ The theoretical framework proposed in the next section does not yield implications that are sufficiently sharp to be tested; however, it is useful in order to show the potential role of income inequality on values in a transparent way.

In Section 3, the data sources for the subsequent analysis are described. We deal with the estimation strategy in Section 4. The core of the paper is from Section 5 to Section 10, where six dimensions of value systems are investigated. Each of those sections builds around a set of regressions relating each single dimension of value systems to two measures of income inequality: current inequality and experienced inequality. Estimation results are discussed separately for each dimension of value systems.

The final Section 11 summarizes our result and draws some conclusions. We find that income inequality has no robust effects on civic virtues, obedience, honesty and altruism. There is some evidence that more income inequality decreases tolerance, but that evidence is rather weak. The only robust effect we find is about the work ethic: a more unequal income distribution tends to strengthen the work ethic of the population.

\footnotetext{
${ }^{4}$ Another possibility would be to follow Bisin and Verdier (2000, 2001), who model both the transmission of cultural traits from parents to children and the influence of horizontal socialization. Akerlof and Kranton (2000, 2005) employ a related notion of identity, which they consider to be partly malleable.
} 


\section{Theoretical Framework}

In order to illustrate how income inequality may matter for value formation, we employ the theory of symbolic values developed by Corneo and Jeanne (2009, 2010). In that approach, a value system is a mapping from a set of judgeable types onto the real orthant. Let $\theta \in\{1, . . \Theta\}$ denote a, possibly multidimensional, type and $v_{\theta} \geq 0$ denote its symbolic value. As values are intrinsically relative, use the normalization $\sum v_{\theta}=1$, i.e. let any individual's value system $\left\{v_{\theta}\right\}_{\theta=1, \ldots \Theta}$ belong to the $\Theta-1$-simplex. Each value system is supposed to be chosen by the individual's parents so as to maximize an objective function, e.g. their child's expected utility. Values matter to individuals because they affect the esteem they receive from others as well as their self-esteem. An individual's self-esteem is the value of her type according to her value system. Esteem received from others depends on others' values about one's type.

The simplest case to handle is the one where parents are altruistic and the individuals' types are exogenous but unknown at the time values are instilled. We focus on that case since it is sufficient in order to illustrate how income inequality may affect values.

Posit a parents' generation that chooses values for their children and a children's generation that will experience some income inequality in adulthood. Every generation consists of a continuum of individuals and every parent has one offspring. Parents know their own income and correctly anticipate what the income distribution will be for the next generation but are uncertain about their children's income. There are $Z$ possible income levels, denoted by $y_{z}$. The income distribution is described by the shares of population that receive the various income levels. Let the children's income distribution be given by the shares $f\left(y_{z}\right)$, with $\sum f=1$.

Every parent selects her child's values so as to maximize the utility that the child is expected to derive from self-esteem, which is assumed to be separable from the remaining arguments in the utility function. We denote utility from self-esteem by $u\left(v_{t}\right)$, where $v_{t}$ is the value of the child's type $t$ according to the child's value system and $u^{\prime}>0>u^{\prime \prime}$.

Denote by $\pi(\theta)$ the subjective probability of type $\theta$. Parents solve the problem

$$
\max \sum_{\theta=1}^{\Theta} \pi(\theta) u\left(v_{\theta}\right) .
$$

subject to

$$
\sum_{\theta=1}^{\Theta} v_{\theta}=1
$$




$$
v_{\theta} \geq 0
$$

From the usual Kuhn-Tucker conditions, the optimal value system is characterized by

$$
\begin{aligned}
& \pi(\theta) u^{\prime}\left(v_{\theta}\right)=\lambda \text { if } v_{\theta}>0 \\
& \pi(\theta) u^{\prime}\left(v_{\theta}\right) \leq \lambda \text { if } v_{\theta}=0,
\end{aligned}
$$

for some Lagrange multiplier $\lambda$.

The notion that income inequality can affect values depends on the income level containing some information about the individual's type. Denote the conditional distribution of children's types by

$$
p_{z}(\theta)=\operatorname{Pr}\left(\theta \mid y=y_{z}\right),
$$

where $\sum_{\theta} p_{z}(\theta)=1$ for each $z$. The effect from inequality hinges on parents' ability to forecast their children's income, something which can be apprehended in terms of intergenerational income mobility. Two polar cases may be examined: a perfectly mobile society and a perfectly immobile society.

In a perfectly mobile society, parents' incomes contain no information about their children's incomes. Every child has the same probability to receive a given income level as everybody else and that probability equals the fraction of the children's generation that receives that income ex post. Thus, $\pi(\theta)=\sum_{z} f\left(y_{z}\right) p_{z}(\theta)$ and children's expected utility from self-esteem reads

$$
U=\sum_{z=1}^{Z} \sum_{\theta=1}^{\Theta} f\left(y_{z}\right) p_{z}(\theta) u\left(v_{\theta}\right) .
$$

The optimality conditions of parents' optimization problem can then be written as

$$
\begin{aligned}
& \sum_{z=1}^{Z} f\left(y_{z}\right) p_{z}(\theta) u^{\prime}\left(v_{\theta}\right)=\lambda \text { if } v_{\theta}>0 \\
& \sum_{z=1}^{Z} f\left(y_{z}\right) p_{z}(\theta) u^{\prime}\left(v_{\theta}\right) \leq \lambda \text { if } v_{\theta}=0
\end{aligned}
$$

which immediately show that the shape of the income distribution, as given by the $f\left(y_{z}\right) \mathrm{s}$, generally influences value systems. Income inequality has no impact on values if and only if it contains no information about types, i.e. $p_{z}(\theta)=p(\theta)$ for all $z$ and all $\theta$.

Let us turn to the opposite case of perfect immobility, where a parent's income class $z$ is transmitted to her child with certainty. In this case, the child's expected utility reads

$$
U=\sum_{\theta=1}^{\Theta} p_{z}(\theta) u\left(v_{\theta}\right) \text {. }
$$

In contrast to the former case, income inequality plays no role in shaping the value systems. 
In the general case, intergenerational income mobility may be possible but less than perfect, and be described by a transition matrix. Income inequality will play a role in shaping values and one could investigate how various indexes of income inequality impinge upon values, contingent on the degree of intergenerational income mobility.

To close this modelling part, briefly consider the determination of values in case of logarithmic utility: $u\left(v_{\theta}\right)=\ln v_{\theta}$. In this case, as soon as $\pi(\theta)>0$, optimal values have $v_{\theta}>0$. Straightforward manipulations of the FOCs yield

$$
v_{\theta}=\pi(\theta) \quad \forall \theta
$$

Notice that the child's indirect utility amounts to $\sum_{\theta} \pi(\theta) \ln \pi(\theta)$. In case of perfect information, the parent would invest all value in the child's type and the child's utility would be 0 . The utility increase generated by information about type is thus

$$
H=-\sum_{\theta=1}^{\Theta} \pi(\theta) \ln \pi(\theta)
$$

which is the amount of information about the state of the world according to Shannon.

\section{Data}

Information on the values endorsed by individuals is obtained from the European Value Studies and the World Values Survey, together referred to as WVS. The World Values Survey Network provides a harmonized file of European and World Values Surveys, extending over five survey waves carried out around 1981, 1990, 1995, 2000 and 2005. ${ }^{5}$ In addition, the European Values Survey 2008 provides a sixth round of survey data. ${ }^{6}$ In each wave, the entire survey project was conducted over a period of about three years and for each country the year when the survey was actually conducted is known. That year is used in the regressions discussed in this paper: directly, as a control for time fixed effects, and indirectly, since income inequality and other macroeconomic variables in the country of the respondent are taken for the year when the survey was actually conducted. The empirical analysis is restricted to OECD countries in order to reduce problems of data quality and comparability. As a result, the WVS sample analyzed in this paper covers about 190,000 individuals surveyed during a period of 29 years in 34 countries.

From the WVS data, we recover individually endorsed values pertaining to the following six domains: work ethic, civism, obedience, honesty, altruism, tolerance. Each dimension of

\footnotetext{
${ }^{5}$ For details see http://www.worldvaluessurvey.org.

${ }^{6}$ For details see http://www.europeanvaluesstudy.eu.
} 
an individual's value system is measured by means of responses given to one or more survey questions. Average reported values by country and wave are shown in the Appendix A.

Income inequality in a given country and year is measured by the corresponding Gini coefficient. That variable is taken from the Standardized World Income Inequality Database (SWIID). ${ }^{7}$ The SWIID improves upon older collections of international income inequality datasets, like Deininger and Squire (1996) and the World Income Inequality Database from UN-WIDER and aims at minimizing problems associated with secondary data on income inequality as discussed by Atkinson and Brandolini (2001). The benchmark for standardization is the Luxembourg Income Study dataset which uses household adultequivalent income. Accordingly, the measure of inequality used throughout this paper is the Gini coefficient of household adult-equivalent net income. The Gini coefficients of net income for all OECD countries with corresponding observations in the WVS are shown in Appendix B.

Information about country-level macro variables is obtained from the OECD and the World Bank. Since those two sources use slightly different definitions for some variables, estimations were conducted separately with macro data from the OECD and the World Bank, with both datasets being compiled in 2011. Since the estimation results concerning income inequality are very similar, we only present those obtained using the OECD data.

\section{Estimation Strategy}

The effect of income inequality on endorsed values is estimated using a set of stepwise richer models. A set of six models is called a configuration. A basic configuration is progressively augmented in order to enlarge the analysis and examine the robustness of results.

For binary dependent variables, we estimate logit models. If dependent variables have an ordinal coding, ordered logit estimations are conducted. ${ }^{8}$ The models in what we refer to as the basic (B) configuration can be summarized by:

$$
\begin{gathered}
V_{i c t}^{*}=\alpha+\beta G i n i_{c t}+\gamma_{c}+\lambda^{\prime} X_{i c t}+\varepsilon_{i c t} \\
\operatorname{Pr}\left(V_{i c t}=1\right)=\operatorname{Pr}\left(V_{i c t}^{*}>0\right)
\end{gathered}
$$

The value $V$ endorsed by individual $i$ at time $t$ in country $c$ is explained by the Gini coefficient at time $t$ in country $c$, a set of individual control variables $\boldsymbol{X}$ and country fixed

\footnotetext{
${ }^{7}$ The construction of the SWIID is explained in Solt (2009).

${ }^{8}$ We also ran OLS regressions, which delivered very similar results. They can be obtained from the authors upon request.
} 
effects. To control for unobserved heterogeneity across countries and idiosyncrasies due to the way in which survey questions are translated in the various languages, country dummies are included in all estimations. As shown by Moulton (1990), the inclusion of macro variables in the estimation of micro data can bias standard errors. Accordingly, all standard errors are corrected for clustering at the country level.

The six models in the basic configuration become stepwise richer by including more regressors into $\boldsymbol{X}$. In model (1), vector $\boldsymbol{X}$ only includes gender, age, and age squared, which are all unambiguously exogenous traits. Further models insert additional individual controls for which a mutual influence with the values endorsed by the individual cannot a priori be excluded. By including more regressors, the number of observations used in the regressions is typically reduced because of individually missing items or because some surveys did not collect the corresponding information. In model (2), also the educational achievements of respondents are included. Model (3) adds dummies for quintiles of a respondent's household income. In model (4), dummies for family status and status in the labor market are included. Model (5) adds dummies for the frequency of attendance to religious services, which are substituted in model (6) with dummies for town size. All control variables are described in some detail in Appendix C.

The six models of the basic configuration do not control for macroeconomic variables. Augmenting those models with controls for the log of real per capita GDP, the unemployment rate, and the real growth rate of GDP yields the $B+$ Macro (M) configuration. Per capita GDP captures the aggregate level of economic prosperity in the respondent's country; the unemployment rate is a basic indicator of inefficiency in the allocation of human resources; the growth rate of GDP in the year the survey was conducted captures the position of the country in the business cycle. ${ }^{9}$

Neither the basic configuration nor the basic configuration with macro controls includes time dummies. The measured impact of inequality thus refers to the effect of inequality changes over time. The final configuration, which is called the $B+M+$ Year $F E$ configuration, controls instead also for the year in which the survey was conducted. Since country effects are always included, the estimated effect from income inequality in this configuration is merely due to the variation of the intertemporal changes of the countryspecific Gini coefficients.

We investigate the effects on values from two dimensions of income inequality. First, we use the contemporaneous Gini coefficient and explore the relationship between values

\footnotetext{
${ }^{9}$ Summary statistics for macro variables are also presented in Appendix C.
} 
expressed in a given country in a given year and the income inequality observed in the same country in the same year. Contemporaneous inequality might affect values if it was expected in the past by parents when they raised their children. Second, we replace the contemporaneous Gini coefficient by the average Gini coefficient when the respondent was young, i.e. aged eighteen to twenty-five. This is based on the idea that experiences during that period of life exert an especially strong influence on future attitudes of individuals. ${ }^{10}$

\section{Work Ethic}

A prominent dimension of value systems concerns an individual's work ethic, understood as the symbolic value that an individual attaches to being engaged in the production of goods and services, independently of the utility derived from the monetary remuneration and the concrete conditions under which the work is performed. Against the background of history, work ethic in the above sense seems to be a relatively recent phenomenon. According to the Bible, work was a curse devised by God to punish Adam and Eve for their original sin. Also the slave societies of the Greek polis and ancient Rome regarded work as an inferior activity. Medieval aristocracy used the clergy to try to convince their peasants that work was peasants' duty as decreed by God. The rise of the modern work ethic is usually associated with the development of early capitalism and Protestantism.

At first glance, the implications of a rigid work ethic for economic performance are straightforward. Ceteris paribus, a stronger work ethic will cause individuals to devote a larger share of their time and energy to work, thereby increasing labor supply and output. People looking for a job will do it more intensely if they have a stronger work ethic and they will be less choosy when the available jobs are badly paid; hence, a stronger work ethic will tend to lower the labor costs of firms and reduce the rate of unemployment. On second reflection, the impact of the work ethic on the macroeconomy appears more complex. A too strong work ethic could be harmful for economic growth in advanced knowledge-based economies that rely on human development and an efficient allocation of talent. Obsessions to have a job may lead individuals to avoid risk taking in the choice of their career, possibly sacrificing their personal talent for an occupation if the risk of personal failure is comparatively large. A very strong emphasis on work may be harmful for innovation if some “creative idleness" is a fertile soil for the arrival of new ideas. And compulsive workers may

\footnotetext{
10 See e.g. Giuliano and Spilimbergo (2009) and references therein. We also conducted estimations using the Gini coefficient with a ten-year lag and with a twenty-year lag. Results can be obtained from the authors upon request.
} 
turn out to be more likely to suffer from job-related health problems - from exhaustion to high blood pressure - that eventually undermine their ability to work. For society at large, a heavy stigmatization of the unemployed may prove highly divisive, politically destabilizing and costly in terms of social policy. Altogether, this suggests that the work ethic might have a non-monotonic effect on economic performance, improving it at low levels of work ethic and worsening it at high levels. ${ }^{11}$

\subsection{Work-first}

We use four survey questions from the WVS that proxy an individual's work ethic. The first proxy is called work-first, and is constructed from a survey question where respondents are asked:

Do you agree or disagree with the following statement? Work should always come first, even if it means less spare time. 5 'Strongly agree' 4 'Agree' 3 'Neither agree or disagree' 2 'Disagree' 1 'Strongly disagree'

Arguably, work-first is a good proxy for the work ethic because it directly evaluates whether and to what degree respondents prioritize work over other activities. ${ }^{12}$ Figure 1 plots the average numerical value taken by work-first in the various countries during the entire observation period against the country-specific average of the Gini coefficients in the corresponding years. ${ }^{13}$ The OLS regression line depicted in the figure indicates that income inequality and this proxy of the work-ethic are positively correlated across countries.

Figure 1. Income inequality and work-first across OECD-countries.

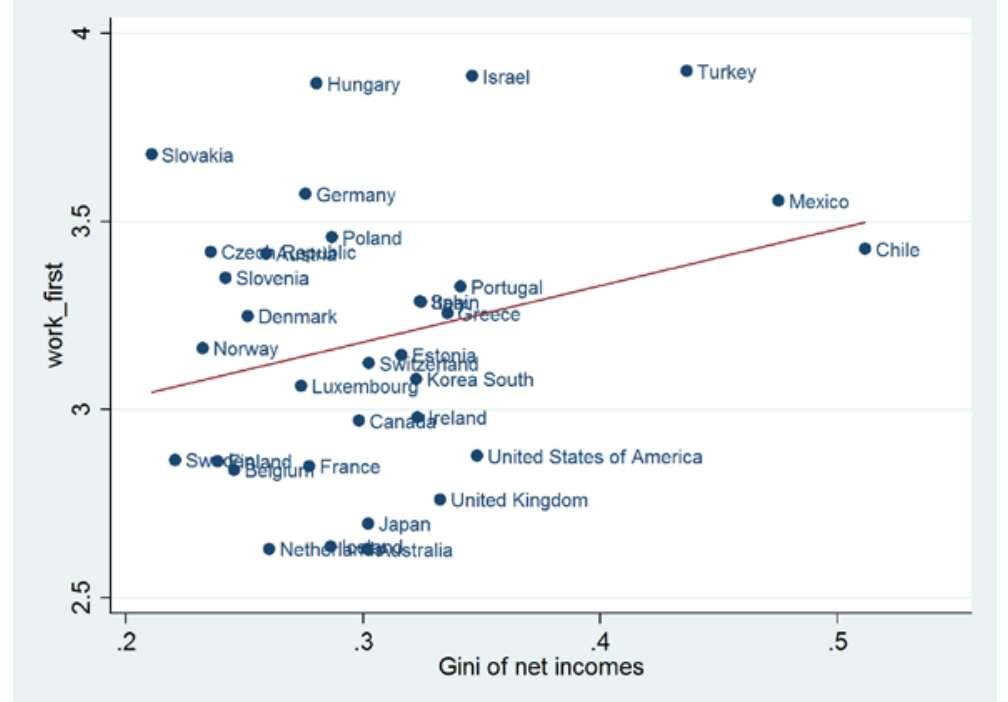

\footnotetext{
${ }^{11}$ Corneo (2012) offers some empirical evidence supporting this.

${ }^{12}$ Gradstein (2009) and Schaltegger and Torgler (2009) use this item to proxy for work attitudes.

${ }^{13}$ All scatter plots in this paper are constructed likewise.
} 
Do changes in income inequality within countries contribute to explain country-specific changes in the work ethic of respondents, as measured by work-first? We follow the empirical strategy presented in Section 4. Since it entails a very large number of regressions, we only report the estimated coefficients for income inequality. We start with results for the contemporaneous Gini coefficient of net incomes. As can be seen from Table 1, income inequality has a positive, strongly significant relation with work-first when macroeconomic controls are excluded (basic configuration, first row). When controlling for the level of economic development, unemployment and yearly GDP growth (second row), results remain uniformly positive and highly significant. Adding time fixed effects (third row) yields positive coefficients, most of them statistically significant at levels of $5-10 \%$. These results clearly suggest that income inequality strengthens the work ethic endorsed by individuals.

Table 1. Coefficients of contemporaneous Gini for work-first

\begin{tabular}{c|cccccc}
\hline & $(1)$ & $(2)$ & $(3)$ & $(4)$ & $(5)$ & $(6)$ \\
\hline Basic & $0.064^{* * *}$ & $0.086^{* * *}$ & $0.088^{* * *}$ & $0.090^{* * *}$ & $0.088^{* * *}$ & $0.089^{* * *}$ \\
& $(3.79)$ & $(4.29)$ & $(5.08)$ & $(5.15)$ & $(4.84)^{* * *}$ & $(4.76)$ \\
B + Macro & $0.064^{*}$ & $0.093^{* * *}$ & $0.099^{* * *}$ & $0.101^{* * *}$ & $0.099^{* * *}$ & $0.106^{* * *}$ \\
& $(2.41)$ & $(3.78)$ & $(4.25)$ & $(4.28)$ & $(4.13)$ & $(4.34)$ \\
B + M + Year FE & 0.045 & $0.063^{*}$ & $0.075^{*}$ & $0.077^{*}$ & $0.073^{+}$ & 0.049 \\
& $(1.28)$ & $(2.07)$ & $(1.96)$ & $(1.97)$ & $(1.85)$ & $(0.82)$ \\
\hline
\end{tabular}

t statistics in parentheses; $+p<0.10,{ }^{*} p<0.05,{ }^{* *} p<0.01,{ }^{* * *} p<0.001$

We now turn to the effect on work ethic generated by income inequality experienced during youth. As shown in Table 2, the effect from that variable on work-first is uniformly positive. However, results are not statistically significant at conventional levels.

Table 2. Coefficients of Gini when aged 18-25 for work-first

\begin{tabular}{c|cccccc}
\hline & $(1)$ & $(2)$ & $(3)$ & $(4)$ & $(5)$ & $(6)$ \\
\hline Basic & 0.008 & 0.005 & 0.005 & 0.005 & 0.006 & 0.005 \\
B + Macro & $(0.97)$ & $(0.58)$ & $(0.53)$ & $(0.55)$ & $(0.66)$ & $(0.56)$ \\
& 0.013 & 0.007 & 0.008 & 0.008 & 0.007 & 0.007 \\
B + M + Year FE & $(1.50)$ & $(0.81)$ & $(0.84)$ & $(0.85)$ & $(0.83)$ & $(0.86)$ \\
& 0.013 & 0.007 & 0.008 & 0.008 & 0.008 & 0.007 \\
& $(1.57)$ & $(0.82)$ & $(0.88)$ & $(0.89)$ & $(0.87)$ & $(0.82)$ \\
\hline
\end{tabular}

t statistics in parentheses; $+p<0.10,{ }^{*} p<0.05,{ }^{* *} p<0.01, * * * p<0.001$

\subsection{Money-work}

The second proxy for the work ethic of respondents is a variable that we label moneywork. It is based on the following survey question: 
Do you agree or disagree with the following statement? It is humiliating to receive money without having to work for it. 5 'Strongly agree' 4 'Agree' 3 'Neither agree nor disagree' 2 'Disagree' 1 'Strongly disagree'.

Respondents who agree with this statement are likely to feel ashamed or guilty when being unemployed and to stigmatize those who live on unemployment benefits or related social transfers. This proxy captures the endorsement of a work norm that dictates selfsupportiveness, i.e. persons who are able to work should work so as to support themselves by their own work. ${ }^{14}$ Figure 2 depicts the correlation of money-work with the Gini coefficient of net incomes across countries.

Figure 2. Income inequality and money-work across OECD-countries.

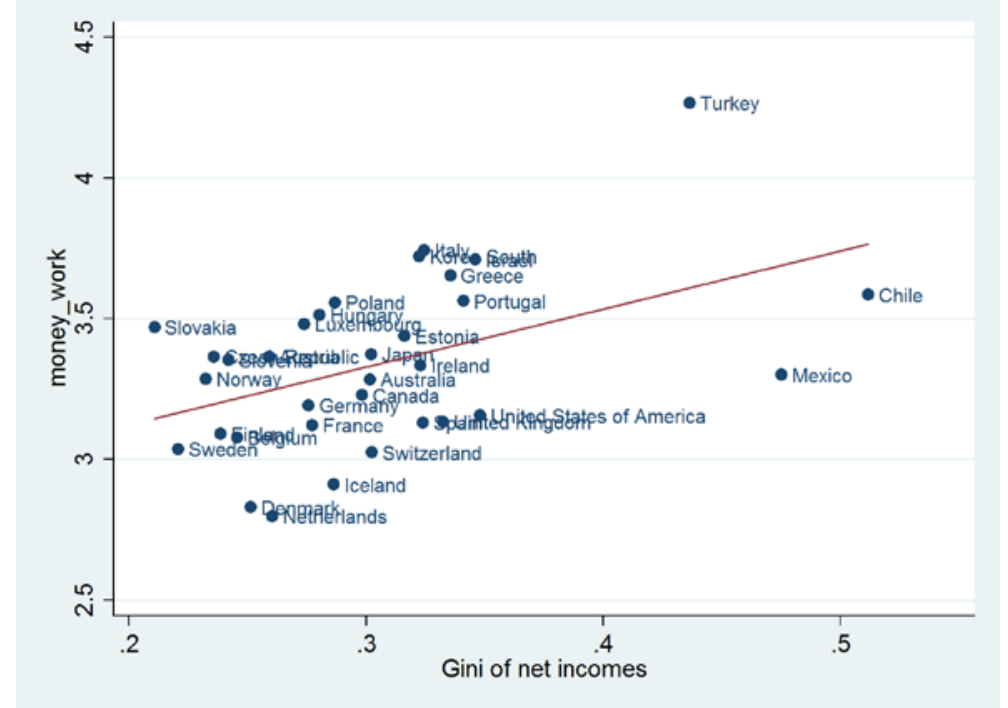

The results from our empirical investigation are shown in Table 3. Accordingly, the contemporaneous Gini coefficient of net income has a positive relation with money-work, significant at levels of $5 \%$ to $10 \%$.

Table 3. Coefficients of contemporaneous Gini for money-work.

\begin{tabular}{c|cccccc}
\hline & $(1)$ & $(2)$ & $(3)$ & $(4)$ & $(5)$ & $(6)$ \\
\hline Basic & $0.053^{*}$ & $0.059^{*}$ & $0.058^{*}$ & $0.061^{*}$ & $0.060^{*}$ & $0.064^{*}$ \\
& $(2.19)$ & $(2.30)$ & $(2.29)$ & $(2.38)$ & $(2.28)$ & $(2.46)$ \\
B + Macro & $0.056^{+}$ & $0.064^{*}$ & $0.062^{*}$ & $0.065^{*}$ & $0.063^{*}$ & $0.069^{*}$ \\
& $(1.91)$ & $(2.18)$ & $(2.09)$ & $(2.13)$ & $(2.05)$ & $(2.37)$ \\
B + M + Year FE & $0.043^{+}$ & $0.049^{*}$ & $0.046^{+}$ & $0.048^{*}$ & $0.045^{+}$ & 0.025 \\
& $(1.94)$ & $(2.19)$ & $(1.95)$ & $(1.97)$ & $(1.88)$ & $(0.70)$ \\
\hline
\end{tabular}

t statistics in parentheses; $+p<0.10,{ }^{*} p<0.05,{ }^{* *} p<0.01, * * * p<0.001$

\footnotetext{
${ }^{14}$ Minkov and Blagoev (2009) use this item in a factor analysis to study the relation between culture and economic growth.
} 
We now turn to the effect of inequality when respondents were aged eighteen to twentyfive. As shown in Table 4, the experience of inequality when young has a positive effect on money-work, but results fail to be statistically significant.

Table 4. Coefficients of Gini when aged 18-25 for money-work.

\begin{tabular}{c|cccccc}
\hline & $(1)$ & $(2)$ & $(3)$ & $(4)$ & $(5)$ & $(6)$ \\
\hline Basic & 0.005 & 0.006 & 0.004 & 0.005 & 0.007 & 0.005 \\
& $(0.82)$ & $(0.86)$ & $(0.57)$ & $(0.67)$ & $(0.95)$ & $(0.69)$ \\
B + Macro & 0.005 & 0.004 & 0.002 & 0.003 & 0.003 & 0.001 \\
& $(0.66)$ & $(0.59)$ & $(0.32)$ & $(0.41)$ & $(0.40)$ & $(0.13)$ \\
B + M + Year FE & 0.004 & 0.003 & 0.002 & 0.002 & 0.002 & 0.001 \\
& $(0.59)$ & $(0.48)$ & $(0.22)$ & $(0.31)$ & $(0.31)$ & $(0.09)$ \\
\hline
\end{tabular}

$t$ statistics in parentheses; $+p<0.10,{ }^{*} p<0.05,{ }^{* *} p<0.01,{ }^{* * *} p<0.001$

Taken all together, results obtained using money-work are remarkably similar to those obtained using work-first. By and large, more income inequality in a country comes with a higher probability that respondents in that country exhibit a stronger work ethic.

\subsection{Work-duty}

The third proxy constructed to capture a respondent's work ethic asks whether work is a duty towards society:

Do you agree or disagree with the following statement? Work is a duty towards society 5 'Strongly agree' 4 'Agree' 3 'Neither agree or disagree' 2 'Disagree' 1 'Strongly disagree'

It is not so clear that this survey question is a good proxy for work ethic as defined above, i.e. the value associated with actively contributing to the production of goods and services for one's employer or the market. An individual may have a strong work ethic in this sense without being convinced that work is a duty towards society. That individual may think that work is a duty towards God or towards his family but not towards society. Conversely, someone with a weak work ethic in the above sense may agree that work is a duty towards society and therefore engage in a lot of volunteering to help the needy or to preserve the natural environment for future generations. ${ }^{15}$ The observed association between average work-duty and the Gini coefficient of net incomes across countries is shown in Figure 3.

\footnotetext{
${ }^{15}$ In fact, Balan and Knack (2011) use work-duty as a proxy for morality in an analysis of the determinants of human capital investment.
} 
Figure 3. Income inequality and work-duty across OECD-countries.

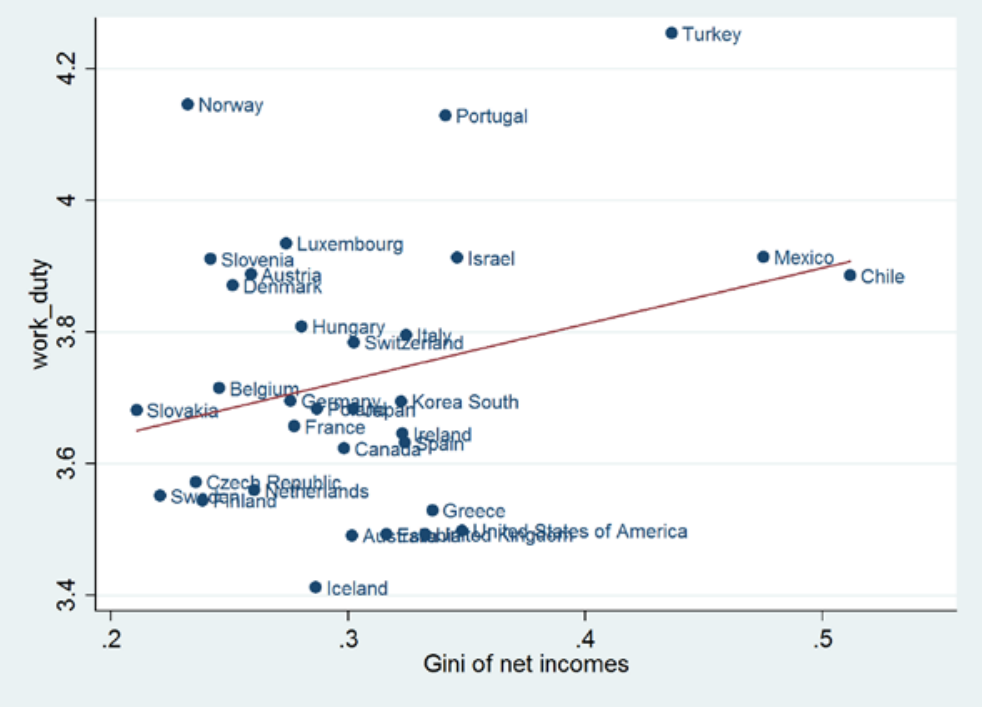

Table 5 reports our estimation results concerning the effect from contemporaneous levels of inequality of net income. The estimated coefficients are mostly positive and often statistically significant.

Table 5. Coefficients of contemporaneous Gini for work-duty.

\begin{tabular}{c|cccccc}
\hline & $(1)$ & $(2)$ & $(3)$ & $(4)$ & $(5)$ & $(6)$ \\
\hline Basic & $0.060^{* *}$ & $0.070^{* *}$ & $0.068^{* *}$ & $0.071^{*}$ & $0.068^{*}$ & $0.069^{*}$ \\
& $(3.02)$ & $(2.81)$ & $(2.60)$ & $(2.57)^{* *}$ & $(2.29)^{*}$ & $(2.33)$ \\
B + Macro & $0.071^{* * *}$ & $0.084^{* * *}$ & $0.080^{* * *}$ & $0.082^{* * *}$ & $0.080^{* * *}$ & $0.084^{* * *}$ \\
& $(4.75)$ & $(4.81)$ & $(4.03)$ & $(3.84)$ & $(3.44)$ & $(3.51)$ \\
B + M + Year FE & $0.058^{*}$ & $0.065^{*}$ & 0.024 & 0.025 & 0.019 & -0.013 \\
& $(2.24)$ & $(2.39)$ & $(0.98)$ & $(0.97)$ & $(0.72)$ & $(-0.32)$ \\
\hline
\end{tabular}

$t$ statistics in parentheses; $+p<0.10,{ }^{*} p<0.05,{ }^{* *} p<0.01, * * * p<0.001$

The average level of income inequality experienced by respondents when aged eighteen to twenty-five also produces positive coefficients, see Table 6; however they lack statistical significance.

Table 6. Coefficients of Gini when aged 18-25 for work-duty.

\begin{tabular}{c|cccccc}
\hline & $(1)$ & $(2)$ & $(3)$ & $(4)$ & $(5)$ & $(6)$ \\
\hline Basic & 0.009 & 0.008 & 0.008 & 0.008 & 0.009 & 0.007 \\
B + Macro & $(1.21)$ & $(1.15)$ & $(1.01)$ & $(1.07)$ & $(1.14)$ & $(0.98)$ \\
& 0.011 & 0.009 & 0.009 & 0.010 & 0.009 & 0.009 \\
B + M + Year FE & $(1.39)$ & $(1.17)$ & $(1.13)$ & $(1.21)$ & $(1.13)$ & $(1.12)$ \\
& 0.011 & 0.009 & 0.010 & 0.010 & 0.010 & 0.009 \\
& $(1.45)$ & $(1.21)$ & $(1.22)$ & $(1.31)$ & $(1.23)$ & $(1.06)$ \\
\hline
\end{tabular}

$t$ statistics in parentheses; $+p<0.10, * p<0.05,{ }^{* *} p<0.01,{ }^{* * *} p<0.001$ 


\subsection{Child-hardwork}

A final proxy for the work ethic is the variable child-hardwork, a binary variable indicating whether respondents think that teaching children to work hard is important. ${ }^{16}$ Hard work is an element in a list of eleven qualities from which respondents can choose up to five. The corresponding survey question reads:

Here is a list of qualities that children can be encouraged to learn at home. Which, if any, do you consider to be especially important? Please choose up to five.

Hard Work; 0 'Not mentioned' 1 'Important'.

A few caveats are in order. While it is likely that respondents with a stronger work ethic mention hard work as an important quality, this is by no mean obvious. Respondents with a strong work ethic may reason that their children should not be encouraged to learn the importance of hard work because children will live in a society where hard work does not pay in monetary terms. Conversely, an individual who personally disvalues hard work may want children to have a strong work ethic because hard work will be necessary in order for them to have economic success - and, possibly, because this raises the probability for the respondent to be helped by his children once they are adults. This survey item might then be seen as a proxy for the work ethic of the respondents' children rather than of the respondents themselves. Another source of ambiguity is the reference to the home as to the place where a particular quality can be learnt. Additionally to the family, children may learn values from their peers, at school, in the church, and so on. Thus, two individuals who want their children to have the same value system may react in different ways to that survey question because their children face different social environments. By way of an example, a parent with a strong work ethic may fail to mention hard work in that survey question if her children are already taught work diligence by their teachers in school. Figure 4 depicts average work-ethic constructed from the considered variable and income inequality across countries.

\footnotetext{
${ }^{16}$ This empirical measure of work ethic has also been used by Lindbeck and Nyberg (2006) and Maystre et al. (2009).
} 
Figure 4. Income inequality and child-hardwork across OECD-countries.

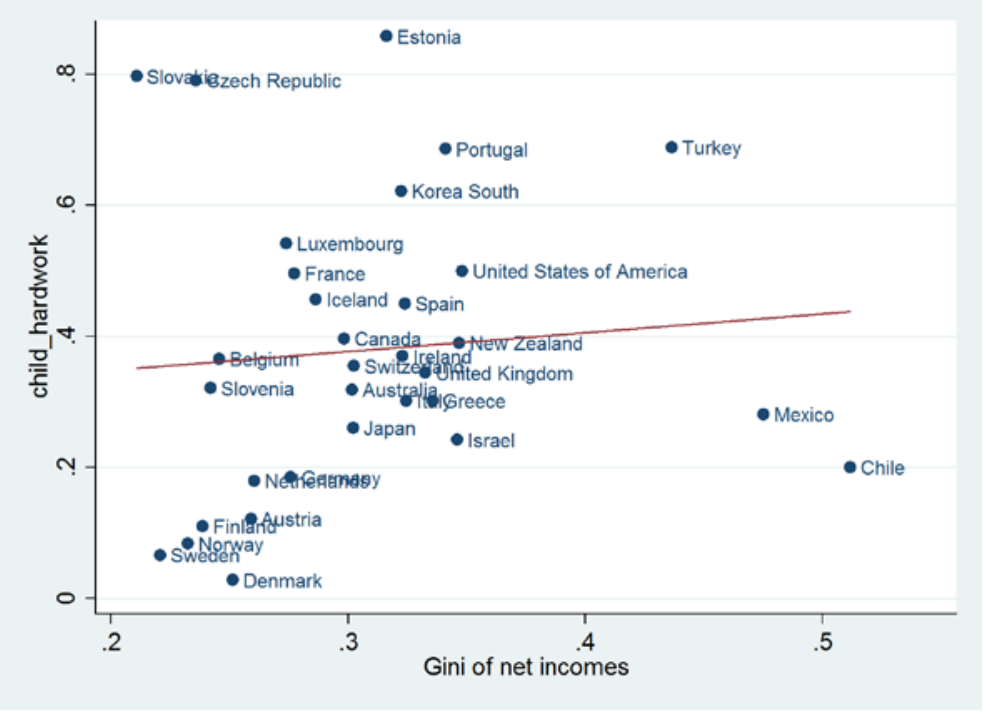

When estimating the effect from contemporary inequality levels, we find a positive relation for all specifications, see Table 7 . Most estimates are statistically significant at conventional levels. ${ }^{17}$

Table 7. Coefficients of contemporaneous Gini for child-hardwork.

\begin{tabular}{c|cccccc}
\hline & $(1)$ & $(2)$ & $(3)$ & $(4)$ & $(5)$ & $(6)$ \\
\hline Basic & $0.066^{+}$ & $0.072^{*}$ & $0.064^{*}$ & $0.079^{* *}$ & $0.077^{* *}$ & 0.099 \\
& $(1.90)$ & $(2.21)$ & $(2.48)$ & $(3.10)$ & $(3.00)$ & $(1.56)$ \\
B + Macro & $0.071^{*}$ & $0.072^{*}$ & $0.067^{*}$ & $0.071^{+}$ & $0.069^{+}$ & $0.089^{*}$ \\
& $(2.49)$ & $(2.01)$ & $(2.27)$ & $(1.93)$ & $(1.90)$ & $(2.09)$ \\
B + M + Year FE & $0.075^{* *}$ & $0.082^{*}$ & $0.086^{* *}$ & $0.082^{* *}$ & $0.080^{* *}$ & 0.063 \\
& $(2.69)$ & $(2.28)$ & $(2.80)$ & $(2.72)$ & $(2.82)$ & $(1.29)$ \\
\hline
\end{tabular}

t statistics in parentheses; $+p<0.10, * p<0.05, * * p<0.01, * * * p<0.001$

We now turn to the effect on the work ethic generated by inequality experienced during youth. As shown by Table 8, the mean value of income inequality when agents have been aged eighteen to twenty-five has a positive relation with child-hardwork, with most coefficients being statistically significant.

\footnotetext{
${ }^{17}$ The reported results were derived from estimations that exclude Hungary and Poland. As can be seen from Table C4 in the Appendix, data from those two countries exhibits a very erratic behavior, depending on whether the European Values Survey or the World Values Survey is the data source, as they worded the question differently. Including Hungary and Poland in the regressions reduces the level of statistical significance of the coefficient of interest but does not change its sign.
} 
Table 8. Coefficients of Gini when aged 18-25 for child-hardwork.

\begin{tabular}{c|cccccc}
\hline & $(1)$ & $(2)$ & $(3)$ & $(4)$ & $(5)$ & $(6)$ \\
\hline Basic & 0.016 & 0.003 & 0.007 & 0.006 & 0.004 & 0.008 \\
& $(1.62)$ & $(0.57)$ & $(1.01)$ & $(0.89)$ & $(0.69)$ & $(1.15)$ \\
B + Macro & $0.019^{* * *}$ & $0.010^{+}$ & $0.014^{* *}$ & $0.012^{* *}$ & $0.012^{* *}$ & $0.012^{*}$ \\
& $(3.32)$ & $(1.91)$ & $(3.00)$ & $(2.71)$ & $(2.59)$ & $(2.35)$ \\
B + M + Year FE & $0.021^{* * *}$ & 0.009 & $0.013^{*}$ & $0.012^{*}$ & $0.011^{*}$ & $0.011^{+}$ \\
& $(4.16)$ & $(1.60)$ & $(2.56)$ & $(2.42)$ & $(2.30)$ & $(1.90)$ \\
\hline
\end{tabular}

$t$ statistics in parentheses; $+p<0.10, * p<0.05, * * p<0.01, * * * p<0.001$

All in all, the analysis in this section delivers quite strong evidence in support of a positive effect from inequality of net incomes on the work ethic endorsed by the population. We have found that inequality during the same year definitively has a positive effect on the work ethic reported by individuals. Income inequality at the time the respondent was young has often been found to be positively correlated with the work ethic, but the effect is often not significant. We discuss the implications of those findings in the final Section 11.

\section{Civism}

Civism refers to that part of an individual's value system that evaluates behavior towards the polity. It shapes attitudes about complying with rules and laws independently of their enforcement through police and tribunals. Civic virtues include paying taxes, rejecting bribes, testifying before courts, and voting on political elections.

As a general presumption, stronger civic virtues are thought to favor macroeconomic performance since more cooperation obtains at lower social costs. In this vein, Guiso et al. (2010) propose a concept of civic capital and argue that civic capital can explain persisting differences in economic performance across countries. However, the notion that civic values are good for the economy does not go completely undisputed. Paying bribes to avoid a queue can increase overall efficiency by having those with the highest opportunity cost of time being served first. In Leviathan or predatory states, tax evasion can be necessary for economic initiative to flourish. Moreover, the public institutions that emerge in a country are themselves likely to be the result of the values endorsed by its citizens. Supporting this, Algan and Cahuc (2009) show that countries with stronger civic values tend to have more generous unemployment benefits and less strict regulations for job protection.

From the WVS one can construct four proxies for civic values that emphasize various aspects of those values. All are used in the subsequent investigation of the effect of income inequality on civism. Each item refers to the justifiability of a specific behavior towards the polity. 
Their common part reads:

Please tell me for each of the following statements whether you think it can always be justified (1), never be justified (10), or something in between, using this card.

The single statements are:

Claiming government benefits to which you are not entitled to.

Avoiding a fare on public transport.

Cheating on taxes if you have a chance.

Someone accepting a bribe in the course of their duties.

These items will now be investigated in turn. ${ }^{18}$

\subsection{Justify-govbenefit}

Let civism be measured by the respondent's attitude towards the justifiability of claiming government benefits to which he is not entitled to. Notice that a higher number in the scale from 1 to 10 indicates a stronger civic value. The observed combination of average benefit moral and the inequality of incomes across countries is shown in Figure 5.

Figure 5. Income inequality and justify-govbenefit across OECD-countries.

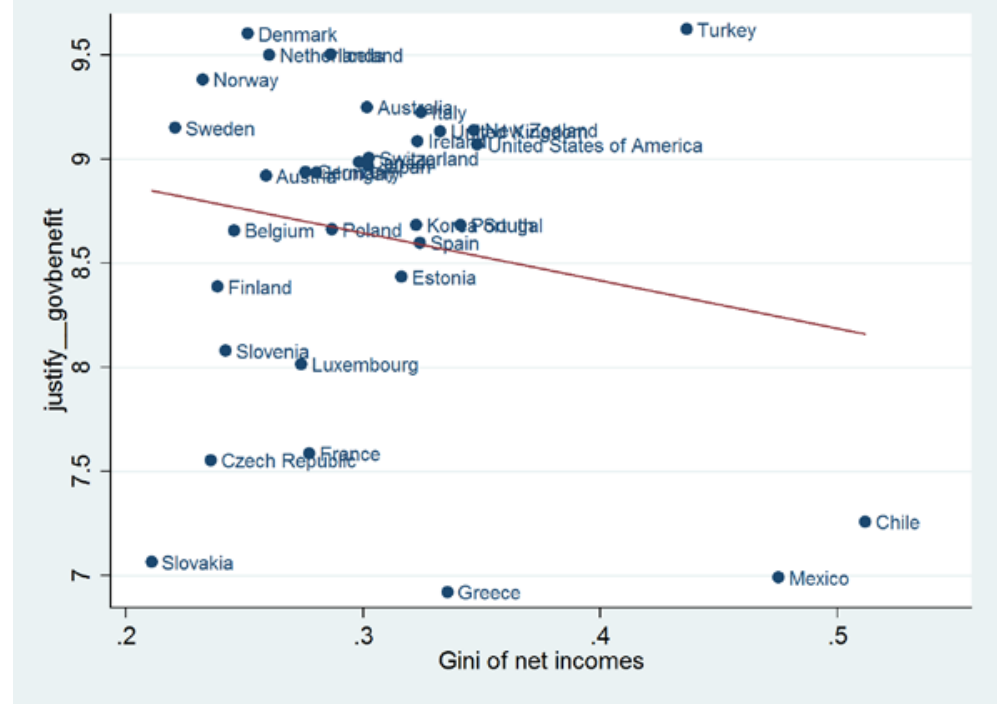

\footnotetext{
${ }^{18}$ Knack and Keefer (1997) used cheating on benefits, on taxes and on fares and other variables to construct a measure of civic cooperation to proxy for social capital. Östling (2009) uses those items to proxy for moral values. Other papers that employed those items are Halla et al. (2010), Heinemann (2008), Schneider and Torgler (2006) and You and Khagram (2005).
} 
As shown in Table 9, current income inequality generates no statistically significant impact on benefit morale within countries.

Table 9. Coefficients of contemporaneous Gini for justify-govbenefit

\begin{tabular}{c|cccccc}
\hline & $(1)$ & $(2)$ & $(3)$ & $(4)$ & $(5)$ & $(6)$ \\
\hline Basic & -0.013 & 0.031 & 0.034 & 0.033 & 0.032 & 0.021 \\
& $(-0.63)$ & $(1.04)$ & $(1.24)$ & $(1.17)$ & $(1.15)$ & $(0.56)$ \\
B + Macro & -0.001 & 0.007 & 0.015 & 0.010 & 0.009 & 0.008 \\
& $(-0.07)$ & $(0.35)$ & $(0.87)$ & $(0.52)$ & $(0.44)$ & $(0.37)$ \\
B + M + Year FE & -0.020 & 0.031 & 0.034 & 0.036 & 0.034 & 0.015 \\
& $(-1.61)$ & $(1.50)$ & $(1.62)$ & $(1.60)$ & $(1.49)$ & $(0.55)$ \\
\hline
\end{tabular}

$t$ statistics in parentheses; $+p<0.10,{ }^{*} p<0.05,{ }^{* *} p<0.01,{ }^{* * *} p<0.001$

Results differ if one concentrates on the effect from inequality when aged eighteen to twenty-five (Table 10). In that case, more inequality is found to be harmful for civism and the effect is statistically significant in about one half of the regressions.

Table 10. Coefficients of Gini when aged 18-25 for justify-govbenefit

\begin{tabular}{c|cccccc}
\hline & $(1)$ & $(2)$ & $(3)$ & $(4)$ & $(5)$ & $(6)$ \\
\hline Basic & -0.010 & $-0.009^{+}$ & $-0.011^{*}$ & $-0.011^{* *}$ & $-0.011^{* *}$ & $-0.010^{+}$ \\
& $(-1.60)$ & $(-1.81)$ & $(-2.51)$ & $(-2.60)$ & $(-2.60)$ & $(-1.84)$ \\
B + Macro & -0.009 & -0.007 & $-0.011^{+}$ & $-0.011^{+}$ & $-0.011^{+}$ & -0.009 \\
& $(-1.11)$ & $(-1.16)$ & $(-1.83)$ & $(-1.80)$ & $(-1.80)$ & $(-1.31)$ \\
B + M + Year FE & -0.009 & -0.009 & $-0.013^{*}$ & $-0.011^{+}$ & $-0.011^{+}$ & -0.009 \\
& $(-1.20)$ & $(-1.45)$ & $(-2.17)$ & $(-1.91)$ & $(-1.89)$ & $(-1.25)$ \\
\hline
\end{tabular}

$t$ statistics in parentheses; $+p<0.10, * p<0.05, * * p<0.01, * * * p<0.001$

In sum, results for justify-govbenefit are quite inconclusive. Estimated coefficients display both positive and negative signs and mostly lack statistical significance.

\subsection{Justify-nofare}

The second proxy for a respondent's civism deals with the illegal use of public transportation. Figure 6 shows the respective scatter-plot. This time, we find that the estimated coefficients for the contemporaneous level of inequality are mostly positive (Table 11). Furthermore, the relation between justify-nofare and the Gini of net income is often statistically significant. However, in the one case where the sign of the coefficient is negative, the estimate is strongly significant. 
Figure 6. Income inequality and justify-nofare across OECD-countries.

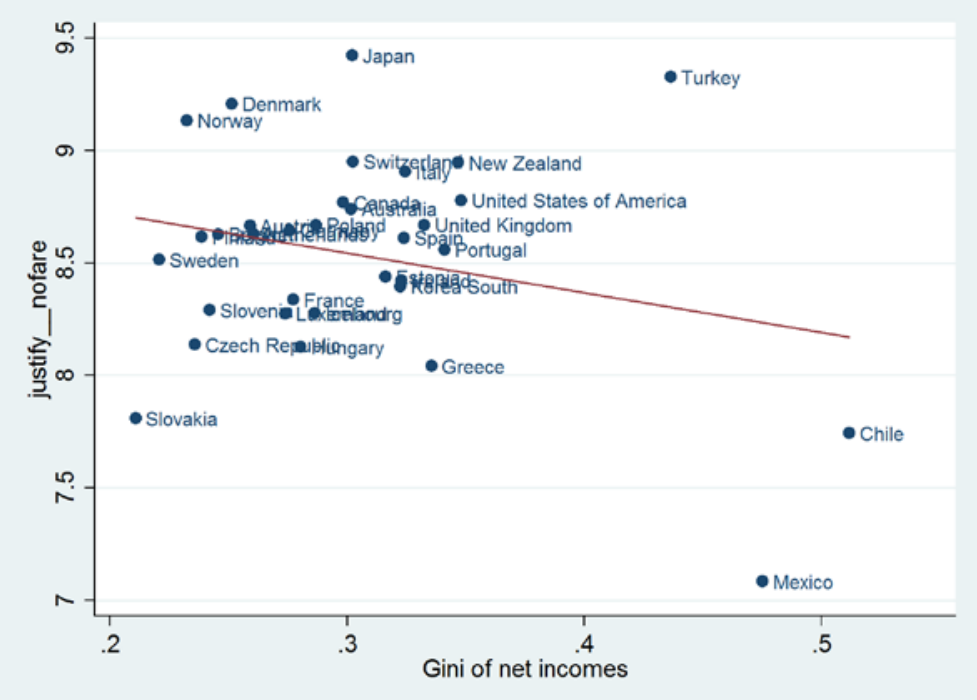

Table 11. Coefficients of contemporaneous Gini for justify-nofare

\begin{tabular}{c|cccccc}
\hline & $(1)$ & $(2)$ & $(3)$ & $(4)$ & $(5)$ & $(6)$ \\
\hline Basic & $-0.054^{* *}$ & $0.052^{+}$ & $0.052^{+}$ & 0.047 & 0.044 & $0.082^{*}$ \\
& $(-3.13)$ & $(1.66)$ & $(1.81)$ & $(1.50)$ & $(1.41)$ & $(2.38)^{* * * *}$ \\
B + Macro & 0.003 & $0.055^{*}$ & $0.067^{* * *}$ & $0.070^{* * *}$ & $0.066^{* *}$ & $0.067^{* * *}$ \\
& $(0.22)$ & $(2.21)$ & $(3.38)$ & $(3.40)$ & $(3.18)$ & $(3.93)$ \\
B + M + Year FE & 0.012 & $0.099^{* * *}$ & $0.100^{* * *}$ & $0.069^{* *}$ & $0.066^{* *}$ & 0.024 \\
& $(0.66)$ & $(5.21)$ & $(5.18)$ & $(3.26)$ & $(3.22)$ & $(0.85)$ \\
\hline
\end{tabular}

$t$ statistics in parentheses; $+p<0.10, * p<0.05,{ }^{* *} p<0.01,{ }^{* * *} p<0.001$

The effect of inequality when aged eighteen to twenty-five is exhibited by Table 12 . There is a mostly negative, but insignificant relation between the mean level of the Gini coefficient of net income while the respondent was young and justify-nofare.

Table 12. Coefficients of Gini when aged 18-25 for justify-nofare

\begin{tabular}{c|cccccc}
\hline & $(1)$ & $(2)$ & $(3)$ & $(4)$ & $(5)$ & $(6)$ \\
\hline Basic & -0.009 & -0.004 & -0.004 & -0.004 & -0.004 & -0.002 \\
& $(-1.23)$ & $(-0.65)$ & $(-0.59)$ & $(-0.52)$ & $(-0.50)$ & $(-0.33)$ \\
B + Macro & 0.000 & -0.002 & -0.004 & -0.004 & -0.004 & -0.001 \\
& $(0.05)$ & $(-0.33)$ & $(-0.65)$ & $(-0.54)$ & $(-0.56)$ & $(-0.13)$ \\
B + M + Year FE & 0.000 & -0.004 & -0.005 & -0.005 & -0.005 & -0.003 \\
& $(0.06)$ & $(-0.54)$ & $(-0.76)$ & $(-0.73)$ & $(-0.73)$ & $(-0.33)$ \\
\hline
\end{tabular}

$t$ statistics in parentheses; $+p<0.10,{ }^{*} p<0.05,{ }^{* *} p<0.01,{ }^{* * *} p<0.001$

In sum, there is a mostly positive relationship between contemporary levels of inequality and a civic attitude towards paying for public transport. However, a mostly negative effect of income inequality is found if the inequality experienced when young is employed as a regressor. 


\subsection{Justify-taxcheat}

The third proxy for civic virtue is constructed from the survey question about cheating on taxes. Average values of justify-taxcheat and the Gini of net incomes are depicted in Figure 7.

Figure 7. Income inequality and justify-taxcheat across OECD-countries.

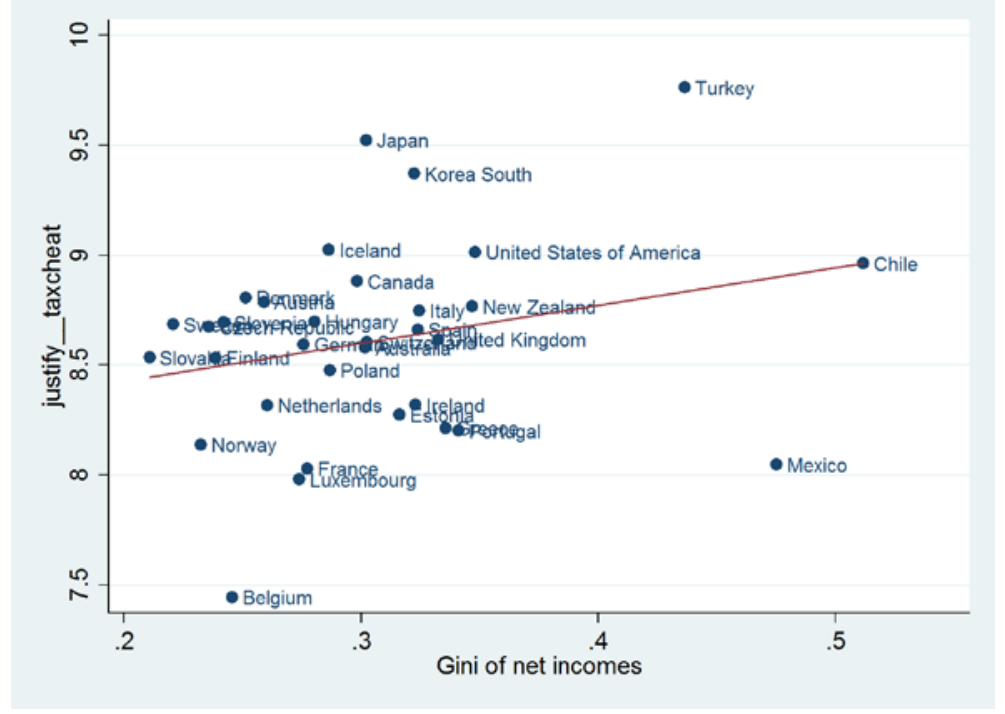

Results for the effect of income inequality are exhibited in Tables 13 and 14. For contemporary measures of income inequality, a mostly positive coefficient is obtained. All results for the configuration with macroeconomic controls without year fixed effects are statistically significant. Higher income inequality seemingly results in stronger tax morals.

Table 13. Coefficients of contemporaneous Gini for justify-taxcheat

\begin{tabular}{c|cccccc}
\hline & $(1)$ & $(2)$ & $(3)$ & $(4)$ & $(5)$ & $(6)$ \\
\hline Basic & -0.007 & 0.045 & 0.042 & 0.039 & 0.037 & 0.051 \\
& $(-0.31)$ & $(1.42)$ & $(1.38)$ & $(1.16)$ & $(1.10)$ & $(1.36)$ \\
B + Macro & $0.026^{+}$ & $0.071^{* *}$ & $0.073^{* *}$ & $0.062^{* *}$ & $0.060^{* *}$ & $0.073^{*}$ \\
& $(1.82)$ & $(3.10)$ & $(3.24)$ & $(2.89)$ & $(2.67)$ & $(2.37)$ \\
B + M + Year FE & -0.000 & $0.046^{*}$ & $0.039^{+}$ & 0.033 & 0.029 & 0.046 \\
& $(-0.03)$ & $(2.03)$ & $(1.81)$ & $(1.48)$ & $(1.28)$ & $(1.23)$ \\
\hline
\end{tabular}

$t$ statistics in parentheses; $+p<0.10, * p<0.05,{ }^{* *} p<0.01,{ }^{* * *} p<0.001$

The average inequality level while being aged eighteen to twenty five does not exhibit a clear relation with tax morale. The estimated coefficients are sometimes positive and sometimes negative and fail to be statistically significant in all but one regression. 
Table 14. Coefficients of Gini when aged 18-25 for justify-taxcheat

\begin{tabular}{c|cccccc}
\hline & $(1)$ & $(2)$ & $(3)$ & $(4)$ & $(5)$ & $(6)$ \\
\hline Basic & $0.009^{*}$ & 0.005 & 0.004 & 0.003 & 0.003 & 0.001 \\
B + Macro & $(1.99)$ & $(1.29)$ & $(1.06)$ & $(0.77)$ & $(0.86)$ & $(0.19)$ \\
& 0.006 & 0.002 & 0.001 & -0.001 & -0.001 & -0.004 \\
B + M + Year FE & $(1.16)$ & $(0.51)$ & $(0.19)$ & $(-0.26)$ & $(-0.25)$ & $(-1.09)$ \\
& 0.005 & -0.001 & -0.002 & -0.002 & -0.002 & -0.003 \\
& $(1.08)$ & $(-0.14)$ & $(-0.65)$ & $(-0.56)$ & $(-0.55)$ & $(-0.77)$ \\
\hline
\end{tabular}

$t$ statistics in parentheses; $+p<0.10,{ }^{*} p<0.05,{ }^{* *} p<0.01,{ }^{* * *} p<0.001$

\subsection{Justify-bribe}

The last proxy for civic values is the justifiability of accepting bribes. The average levels of this value and income inequality across countries are depicted in Figure 8.

Figure 8. Income inequality and justify-bribe across OECD-countries.

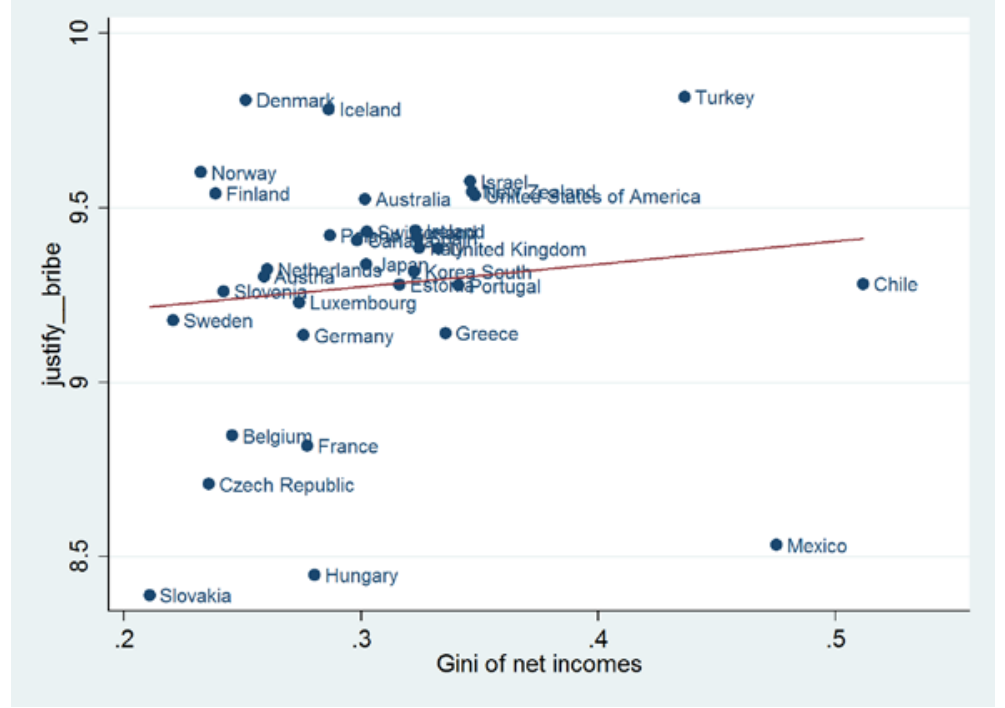

Results about the effect from contemporaneous inequality in Table 15 show a negative relation with justify-bribe, albeit with very little statistical significance. If anything, growing income disparities seem to be harmful for civic virtues in this case.

Table 15. Coefficients of contemporaneous Gini for justify-bribe

\begin{tabular}{c|cccccc}
\hline & $(1)$ & $(2)$ & $(3)$ & $(4)$ & $(5)$ & $(6)$ \\
\hline Basic & -0.002 & -0.004 & -0.002 & -0.010 & -0.012 & -0.018 \\
& $(-0.21)$ & $(-0.15)$ & $(-0.10)$ & $(-0.45)$ & $(-0.53)$ & $(-0.67)$ \\
B + Macro & 0.007 & -0.016 & -0.009 & -0.018 & -0.021 & -0.023 \\
& $(0.38)$ & $(-0.50)$ & $(-0.33)$ & $(-0.65)$ & $(-0.73)$ & $(-0.77)$ \\
B + M + Year FE & -0.016 & -0.043 & -0.056 & $-0.064^{+}$ & $-0.068^{+}$ & -0.052 \\
& $(-0.93)$ & $(-1.20)$ & $(-1.60)$ & $(-1.76)$ & $(-1.86)$ & $(-0.79)$ \\
\hline
\end{tabular}

t statistics in parentheses; $+p<0.10, * p<0.05,{ }^{*} p<0.01, * * * p<0.001$ 
Inequality experienced when young consistently reveals a negative relation between justify-bribe and the Gini coefficient (Table 16). For most estimates, the effect is statistically significant. This is quite in line with the effect from contemporaneous inequality levels.

Table 16. Coefficients of Gini when aged 18-25 for justify-bribe

\begin{tabular}{c|cccccc}
\hline & $(1)$ & $(2)$ & $(3)$ & $(4)$ & $(5)$ & $(6)$ \\
\hline Basic & $-0.010^{*}$ & $-0.013^{*}$ & $-0.016^{* *}$ & $-0.014^{* *}$ & $-0.014^{* *}$ & $-0.013^{*}$ \\
& $(-2.06)$ & $(-2.42)$ & $(-2.95)$ & $(-2.64)$ & $(-2.60)$ & $(-2.32)^{*}$ \\
B + Macro & -0.009 & $-0.012^{+}$ & $-0.017^{*}$ & $-0.014^{*}$ & $-0.014^{*}$ & $-0.015^{*}$ \\
& $(-1.61)$ & $(-1.87)$ & $(-2.53)$ & $(-2.15)$ & $(-2.15)$ & $(-2.17)^{*}$ \\
B + M + Year FE & $-0.009^{+}$ & $-0.013^{*}$ & $-0.017^{* *}$ & $-0.014^{*}$ & $-0.014^{*}$ & $-0.013^{*}$ \\
& $(-1.79)$ & $(-2.10)$ & $(-2.70)$ & $(-2.35)$ & $(-2.33)$ & $(-2.04)$ \\
\hline
\end{tabular}

t statistics in parentheses; $+p<0.10,{ }^{*} p<0.05,{ }^{* *} p<0.01,{ }^{* * *} p<0.001$

To summarize the results from this section, how civism is proxied matters a lot for the estimation results. Using a survey question about free riding on public transport suggests that income inequality might foster civic virtues, whereas using a question about corruption and bribes indicates that more inequality tends to have a negative effect. However, even the results from single proxies are shaky and do not allow to draw firm conclusions. We conclude that on the basis of the data at hand, income inequality is unlikely to be a major determinant of civism.

\section{Obedience}

Obedience presupposes an authority relation. Obedience is stressed in an individual's value system if the individual attaches importance to executing the orders received from a higher level in the relevant hierarchy, e.g. a child obeying his parents, an employee obeying the employer, a common soldier obeying an officer. When obedience carries a symbolic value, the individual feels guilty if he does not follow his superiors' instructions independently of the content of the orders.

The implications of a taste for obedience for economic performance are varied. Obedient workers make firms more flexible since the firm can re-direct the activity of its workers as required by transitory changes in production or market conditions. Thus, for given contractual arrangements between the firm and its employees, more obedience is predicted to reduce production costs. At the aggregate level, a higher output level may obtain from a given employment level.

However, being very obedient entails the risk of being exploited. If an employment contract is very incomplete, i.e. it only loosely specifies the employee's tasks, and assigns 
authority to the employer, the latter has an incentive to use his authority to extract as much labor as possible from the employee. Anticipating this, a very obedient worker has an interest to sign an employment contract where his tasks are rigidly defined so as to avoid being exploited ex post. In situations where - because of market conditions or institutions - the bargaining power of workers is very low, this will not materialize and the firms will profit from an addomesticated, obedient, workforce. If instead workers have enough bargaining power, more respect for authority will come along with contractual arrangements that protect them from ex-post exploitation. The ensuing rigidity will tend to reduce firms' productivity. So, more obedient individuals need not be good for the macroeconomy.

There are two survey questions in the WVS that can be used to proxy an individual's taste for obedience. Each item will now separately be presented and employed in a regression analysis. $^{19}$

\subsection{Child-Obedience}

The first proxy for obedience is an element in a list of eleven non-cognitive child qualities, already used to capture a respondent's work ethic, from which respondents can choose up to five. The survey question reads:

Here is a list of qualities that children can be encouraged to learn at home. Which, if any, do you consider to be especially important? Please choose up to five.

Obedience; 0 'Not mentioned' 1 'Important'.

As can be seen in Figure 9, the fraction of respondents which considers obedience an important child quality increases with a more uneven distribution of net incomes.

\footnotetext{
${ }^{19}$ Inglehart and Welzel (2005) use similar data and interpret a taste for obedience as an element of traditional value systems as opposed to modern ones. See also Maystre et al. (2009), Berry et al. (2009), and Di Tella and Dubra (2010) for papers that employ similar items.
} 
Figure 9. Income inequality and child-obedience across OECD-countries.

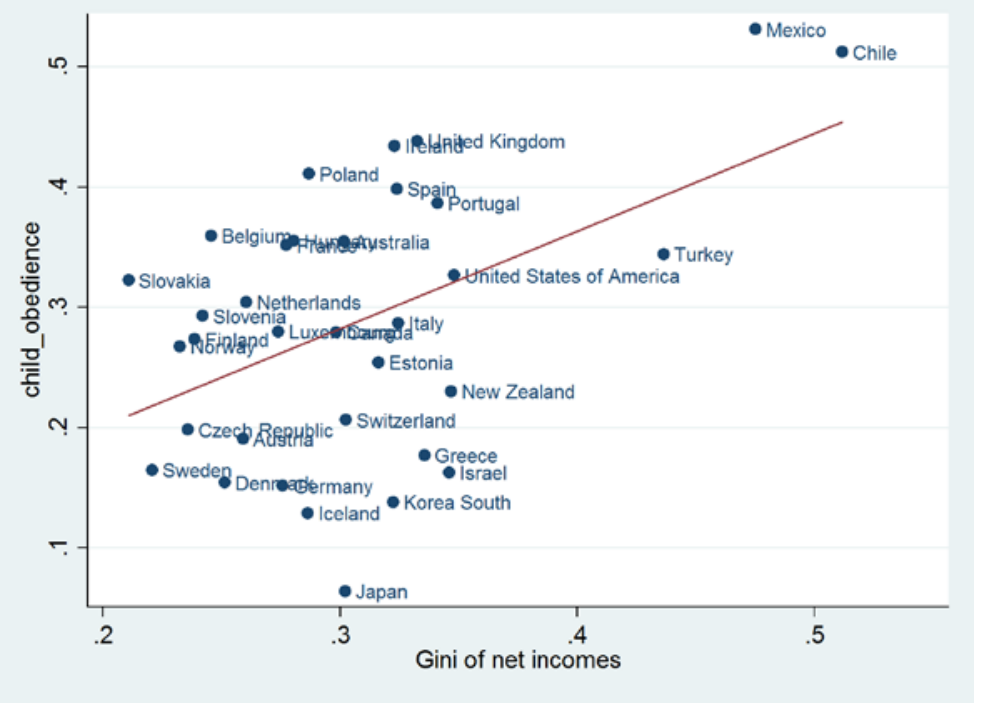

Estimation results are exhibited in Tables 17 and 18. For the current Gini coefficients of net income there is a mostly positive association with obedience. In contrast, inequality levels when young mostly exhibit a negative relationship with obedience. Overall, the obtained results are rather inconclusive as the estimated coefficients are never statistically significant at conventional levels.

Table 17. Coefficients of contemporaneous Gini for child-obedience

\begin{tabular}{c|cccccc}
\hline & $(1)$ & $(2)$ & $(3)$ & $(4)$ & $(5)$ & $(6)$ \\
\hline Basic & -0.000 & 0.027 & 0.026 & 0.029 & 0.026 & 0.021 \\
& $(-0.01)$ & $(0.98)$ & $(1.14)$ & $(1.28)$ & $(1.14)$ & $(0.79)$ \\
B + Macro & -0.022 & 0.035 & 0.035 & 0.011 & 0.010 & 0.011 \\
& $(-1.04)$ & $(1.11)$ & $(1.24)$ & $(0.49)$ & $(0.46)$ & $(0.49)$ \\
B + M + Year FE & -0.008 & 0.042 & 0.026 & 0.010 & 0.010 & 0.065 \\
& $(-0.36)$ & $(1.10)$ & $(0.74)$ & $(0.33)$ & $(0.32)$ & $(1.61)$ \\
\hline
\end{tabular}

$t$ statistics in parentheses; $+p<0.10,{ }^{*} p<0.05,{ }^{* *} p<0.01,{ }^{* * *} p<0.001$

Table 18. Coefficients of Gini when aged 18-25 for child-obedience

\begin{tabular}{c|cccccc}
\hline & $(1)$ & $(2)$ & $(3)$ & $(4)$ & $(5)$ & $(6)$ \\
\hline Basic & 0.001 & -0.003 & -0.003 & -0.002 & -0.002 & 0.000 \\
& $(0.26)$ & $(-0.59)$ & $(-0.51)$ & $(-0.53)$ & $(-0.48)$ & $(0.08)$ \\
B + Macro & 0.001 & -0.003 & -0.003 & -0.001 & -0.002 & -0.004 \\
& $(0.23)$ & $(-0.65)$ & $(-0.59)$ & $(-0.39)$ & $(-0.38)$ & $(-0.80)$ \\
B + M + Year FE & 0.002 & -0.004 & -0.003 & -0.002 & -0.002 & -0.003 \\
& $(0.69)$ & $(-0.99)$ & $(-0.80)$ & $(-0.53)$ & $(-0.57)$ & $(-0.67)$ \\
\hline
\end{tabular}

t statistics in parentheses; $+p<0.10, * p<0.05,{ }^{*} * p<0.01$, *** $p<0.001$ 


\subsection{Instructions-follow}

The second proxy for the value attached to obedience is based on the following survey question:

People have different ideas about following instructions at work. Some say that one should follow one's superior's instructions even when one does not fully agree with them. Others say that one should follow one's superior's instructions only when one is convinced that they are right. With which of these two opinions do you agree?

1 'Must be convinced first' 2 'Depends' 3 'Follow instructions'

Accordingly, an ordinal variable has been constructed that is called instructions-follow. That variable takes value three if the respondent answers "Fellow instructions", two if respondent answers "Depends", and one if the respondent answers "must be convinced first" ${ }^{20}$ A higher value of the variable instructions-follow is therefore interpreted as a higher symbolic value attached to being obedient. As shown in Figure 10, instructions-follow is positively associated with income inequality across countries.

Figure 10. Income inequality and instructions-follow across OECD-countries.

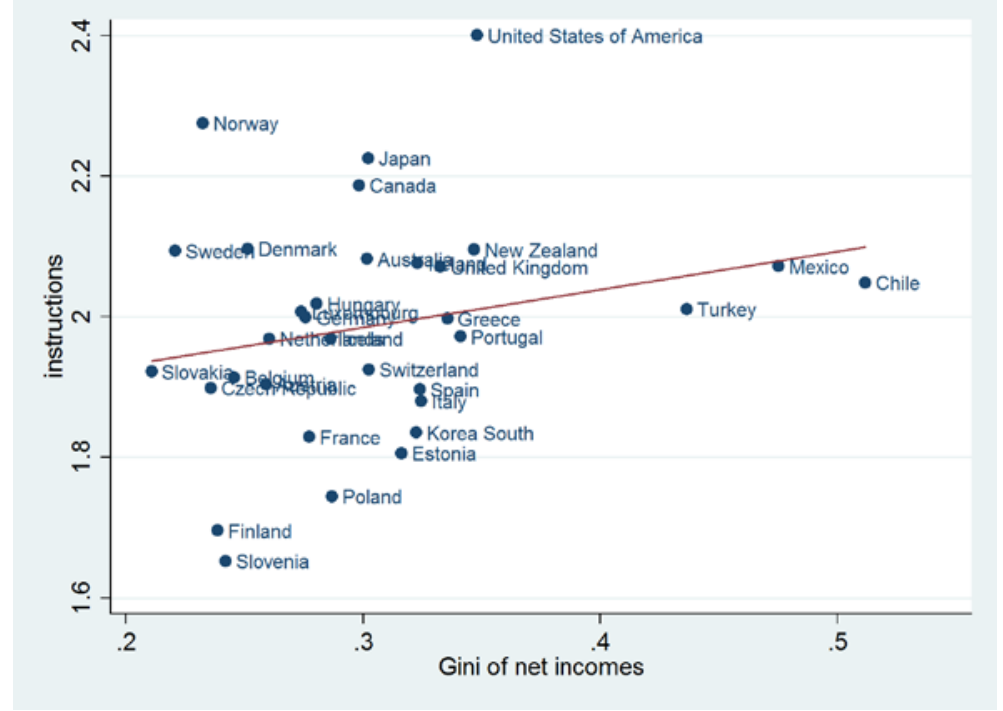

Results about the effect from current inequality indicate that the Gini coefficient of net income has in very few cases a statistically significant, positive relation with instructionsfollow, see Table 19.

\footnotetext{
${ }^{20}$ Estimations were also performed for a binary variable that assigns one to "Follow instructions" and zero otherwise and for a binary variable that assigns one to "Must be convinced first" and zero otherwise. Since results do not vary much from those from instructions-follow, they are not reported here for the sake of brevity.
} 
Table 19. Coefficients of contemporaneous Gini for instructions-follow

\begin{tabular}{c|cccccc}
\hline & $(1)$ & $(2)$ & $(3)$ & $(4)$ & $(5)$ & $(6)$ \\
\hline Basic & 0.004 & -0.001 & -0.008 & 0.004 & 0.003 & 0.022 \\
B + Macro & $(0.33)$ & $(-0.04)$ & $(-0.23)$ & $(0.10)$ & $(0.07)$ & $(0.60)$ \\
& -0.008 & 0.018 & 0.015 & 0.032 & 0.030 & 0.040 \\
B + M + Year FE & $(-0.45)$ & $(0.57)$ & $(0.42)$ & $(0.80)$ & $(0.75)$ & $(1.08)$ \\
& -0.011 & $0.045^{*}$ & 0.043 & $0.048^{+}$ & $0.045^{+}$ & 0.022 \\
& $(-0.65)$ & $(2.01)$ & $(1.63)$ & $(1.85)$ & $(1.75)$ & $(1.57)$ \\
\hline
\end{tabular}

$t$ statistics in parentheses; $+p<0.10,{ }^{*} p<0.05,{ }^{* *} p<0.01,{ }^{* * *} p<0.001$

For inequality levels when young, there is also a positive association between the level of Gini coefficients and instructions-follow (Table 20). Estimated coefficients are always positive but they are statistically significant only for the basic configuration.

Table 20. Coefficients of Gini when aged 18-25 for instructions-follow

\begin{tabular}{c|cccccc}
\hline & $(1)$ & $(2)$ & $(3)$ & $(4)$ & $(5)$ & $(6)$ \\
\hline Basic & $0.009^{* *}$ & $0.007^{+}$ & $0.008^{*}$ & $0.009^{*}$ & $0.009^{*}$ & 0.007 \\
& $(2.72)$ & $(1.77)$ & $(2.02)$ & $(2.34)$ & $(2.47)$ & $(1.36)$ \\
B + Macro & 0.004 & 0.002 & 0.003 & 0.004 & 0.005 & 0.005 \\
& $(0.96)$ & $(0.34)$ & $(0.72)$ & $(0.89)$ & $(1.13)$ & $(0.79)$ \\
B + M + Year FE & 0.004 & 0.001 & 0.003 & 0.003 & 0.004 & 0.004 \\
& $(1.10)$ & $(0.23)$ & $(0.70)$ & $(0.70)$ & $(0.95)$ & $(0.69)$ \\
\hline
\end{tabular}

$t$ statistics in parentheses; $+p<0.10, * p<0.05,{ }^{* *} p<0.01, * * * p<0.001$

Taking our two proxies together, the degree of obedience in a society seems to have at best a weak correlation with income inequality. Higher levels of income inequality might make respondents less critical against the instructions of their superiors. However, there is no evidence of such an effect on the importance to teach obedience to children. Overall, the evidence is mixed, and the effect from inequality on the value of obedience is by no means robust.

\section{Honesty}

The symbolic value of honesty refers to the intrinsic importance attached to truth telling. People raised to be honest feel guilty when lying, whereas people who were differently raised do not care about telling lies. These latter individuals will lie more often if it is in their material interest to do so. In some instances, honesty and civism generate the same normative judgments. Thus, both valuing honesty and valuing civic virtues makes one refrain from declaring less than one's true income for tax purposes. However, civism also refers to civic duties like voting, the violation of which does not entail that one behaves dishonestly. Moreover, honesty goes much beyond the behavior of the individual towards the polity as it also speaks of how individuals relate to other individuals or group of individuals. Thus, some 
persons may be at the same time uncivic towards the polity and violate laws but quite honest when dealing with other persons in economic or social interactions.

Honesty may substantially increase the propensity to conduct market transactions as it reduces the incidence of breach of contracts. The trustworthiness of a society of honest individuals enlarges the scope for labor division and exchange and thereby enhances the whole economy. Honesty also benefits collective decision making since it makes it possible to credibly transmit information that is useful for evaluating alternative policy options. As a result, one may presume that macroeconomic performance increases with the strength of the symbolic value associated to honesty.

To measure the weight attached to honesty, we employ the following survey question:

Please tell me for each of the following statements whether you think it can always be justified, never be justified, or something in between, using this card. (Read out statements. Code one answer for each statement). Lying in your own interest 1 'Never justifiable' 10 'Always justifiable, 21

Figure 11. Income inequality and justify-lying across OECD-countries.

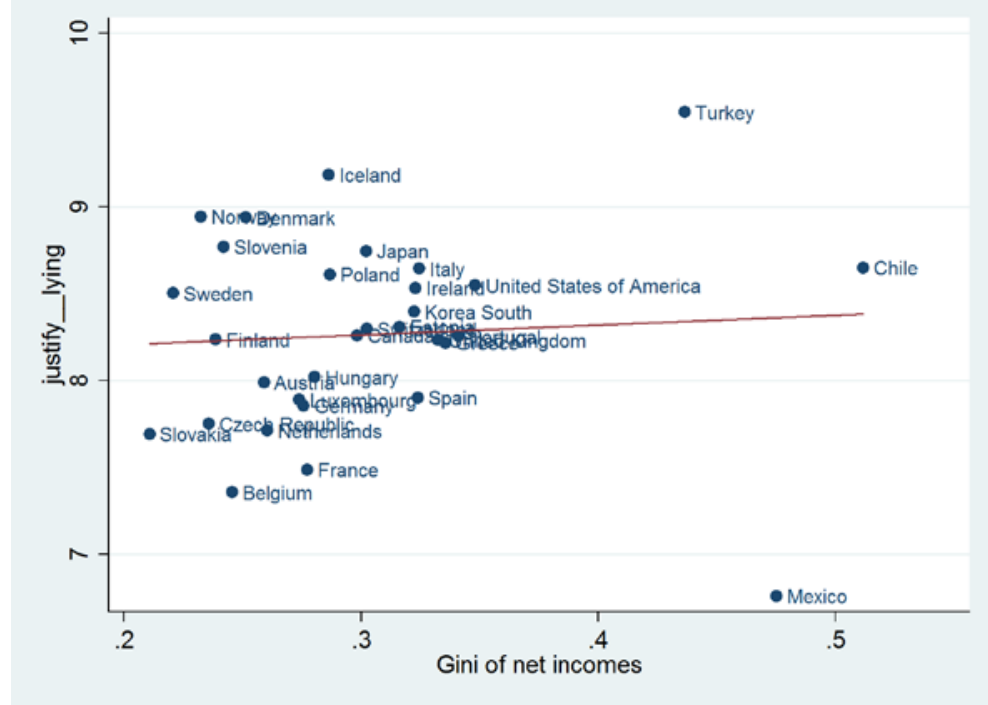

The average values of honesty and income inequality across countries are depicted in Figure 11. Table 21 reports the estimated coefficients for the contemporaneous level of inequality. It shows that the Gini coefficient of net income has a mostly positive and in a few cases significant relation with the item measuring honesty.

\footnotetext{
${ }^{21}$ This survey question among others has been used by Guiso et al. (2010) to construct a measure for civic capital.
} 
Table 21. Coefficients of contemporaneous Gini for justify-lying

\begin{tabular}{c|cccccc}
\hline & $(1)$ & $(2)$ & $(3)$ & $(4)$ & $(5)$ & $(6)$ \\
\hline Basic & -0.018 & 0.020 & 0.025 & 0.028 & 0.028 & 0.018 \\
B + Macro & $(-1.34)$ & $(0.75)$ & $(0.82)$ & $(0.86)$ & $(0.81)$ & $(0.58)$ \\
& 0.018 & $0.048^{* *}$ & $0.056^{* *}$ & $0.061^{*}$ & $0.061^{*}$ & $0.050^{*}$ \\
B + M + Year FE & $(1.05)$ & $(2.84)$ & $(2.62)$ & $(2.44)$ & $(2.25)$ & $(2.18)$ \\
& 0.015 & 0.031 & 0.015 & 0.011 & 0.005 & -0.000 \\
& $(1.00)$ & $(1.05)$ & $(0.41)$ & $(0.29)$ & $(0.13)$ & $(-0.00)$ \\
\hline
\end{tabular}

$t$ statistics in parentheses; $+p<0.10,{ }^{*} p<0.05,{ }^{* *} p<0.01,{ }^{* * *} p<0.001$

All estimated coefficients are negative if inequality is measured by the Gini coefficient experienced when young; however, those coefficients never reach statistical significance (Table 22).

Table 22. Coefficients of Gini when aged 18-25 for justify-lying

\begin{tabular}{c|cccccc}
\hline & $(1)$ & $(2)$ & $(3)$ & $(4)$ & $(5)$ & $(6)$ \\
\hline Basic & -0.004 & -0.004 & -0.003 & -0.005 & -0.004 & -0.003 \\
& $(-0.62)$ & $(-0.71)$ & $(-0.51)$ & $(-0.83)$ & $(-0.77)$ & $(-0.61)$ \\
B + Macro & -0.002 & -0.004 & -0.005 & -0.007 & -0.007 & -0.006 \\
& $(-0.28)$ & $(-0.71)$ & $(-0.81)$ & $(-1.24)$ & $(-1.19)$ & $(-1.06)$ \\
B + M + Year FE & -0.002 & -0.005 & -0.005 & -0.007 & -0.007 & -0.006 \\
& $(-0.32)$ & $(-0.80)$ & $(-0.84)$ & $(-1.18)$ & $(-1.14)$ & $(-1.03)$ \\
\hline
\end{tabular}

$t$ statistics in parentheses; $+p<0.10,{ }^{*} p<0.05,{ }^{* *} p<0.01,{ }^{* * *} p<0.001$

In sum, the taste for truth-telling exhibits a very weak and unstable correlation with income inequality. The data does not support the hypothesis that income inequality affects honesty in a significant way.

\section{Altruism}

An individual's value system may stress the importance of helping others at personal cost when they are in need. We refer to this attitude as altruism. People who are intrinsically altruistic feel bad if they refrain from helping others. Conversely, selfish people do not experience any feeling of guilt in such cases. Altruism is differently explained depending on whether it refers to intra-family ties or to relationships between unrelated individuals. While there is substantial agreement that altruism towards own children and other relatives has a strong basis in natural selection and may somehow be hardwired in the human brain, altruism towards strangers is hard to explain on the basis of natural selection and should mainly be apprehended as a cultural phenomenon.

The economic implications of altruism are complex. In a direct way, altruism entails transfers from the well-to-do to the needy and therefore tends to raise social welfare. This does not mean that economic performance as measured by GDP has to increase. If highly 
productive individuals reduce their working hours in order to volunteer assisting people with social problems, GDP may go down. Furthermore, altruism may engender a Samaritan's problem: the presence of altruists may encourage opportunistic behavior by those who expect to be helped by the altruists. Similarly to extensive welfare arrangements, in an altruistic society some subgroups may remain in a poverty trap because they face no incentive to invest if they get rescued anyway from the altruists. Thus, while altruism may make social interactions more pleasant and be useful as an insurance mechanism, it could possibly worsen macroeconomic performance as usually measured.

In our dataset, unselfishness is an element in a list of eleven qualities from which respondents can choose up to five. The survey question reads:

Here is a list of qualities that children can be encouraged to learn at home. Which, if any, do you consider to be especially important? Please choose up to five.

Unselfishness; 0 'Not mentioned' 1 'Important'. ${ }^{22}$

Figure 12. Income inequality and child-unselfish across OECD-countries.

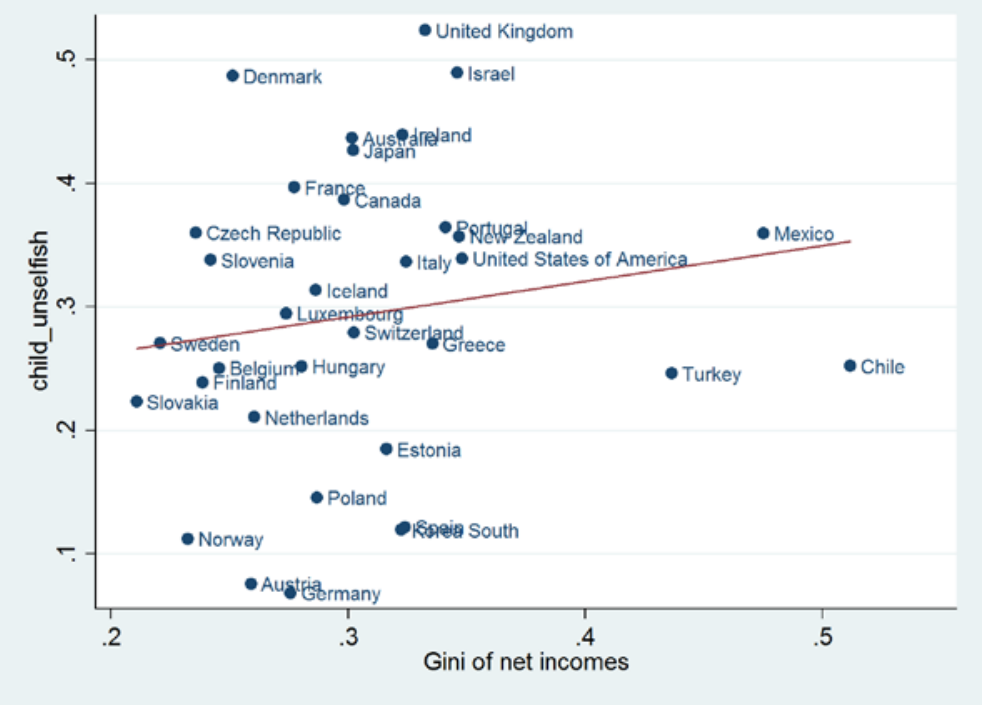

In Figure 12 the average fractions of respondents who find altruism an important child quality are plotted against the Gini coefficient of net incomes. As can be observed in Table 23, results from contemporaneous inequality exhibit mostly positive coefficients. However, those coefficients are almost never statistically significant at conventional levels.

\footnotetext{
${ }^{22}$ Aghion et al. (2010) employ this question to construct an index of civic education. Gorodnichenko and Roland (2011) employ it to build an index of the propensity to contribute to the provision of public goods. See also Maystre et al. (2009).
} 
Table 23. Coefficients of contemporaneous Gini for child-unselfish

\begin{tabular}{c|cccccc}
\hline & $(1)$ & $(2)$ & $(3)$ & $(4)$ & $(5)$ & $(6)$ \\
\hline Basic & $0.047^{+}$ & 0.014 & 0.007 & 0.014 & 0.013 & 0.033 \\
& $(1.93)$ & $(0.67)$ & $(0.34)$ & $(0.58)$ & $(0.53)$ & $(0.99)$ \\
B + Macro & 0.004 & 0.017 & 0.007 & 0.005 & 0.003 & 0.037 \\
& $(0.24)$ & $(0.73)$ & $(0.33)$ & $(0.20)$ & $(0.12)$ & $(0.84)$ \\
B + M + Year FE & -0.013 & 0.018 & 0.008 & 0.003 & 0.003 & 0.038 \\
& $(-0.54)$ & $(0.50)$ & $(0.25)$ & $(0.10)$ & $(0.10)$ & $(0.83)$ \\
\hline
\end{tabular}

$t$ statistics in parentheses; $+p<0.10,{ }^{*} p<0.05,{ }^{* *} p<0.01,{ }^{* * *} p<0.001$

The average level of the Gini coefficient during youth shows a consistent negative relation with the current measure of altruism (Table 24). However, the estimated coefficients are insignificantly different from zero.

Table 24. Coefficients of Gini when aged 18-25 for child-unselfish

\begin{tabular}{c|cccccc}
\hline & $(1)$ & $(2)$ & $(3)$ & $(4)$ & $(5)$ & $(6)$ \\
\hline Basic & 0.000 & -0.005 & -0.003 & -0.004 & -0.004 & -0.005 \\
& $(0.03)$ & $(-1.43)$ & $(-0.81)$ & $(-0.88)$ & $(-0.89)$ & $(-0.97)$ \\
B + Macro & -0.007 & -0.006 & -0.003 & -0.004 & -0.004 & -0.006 \\
& $(-1.64)$ & $(-1.31)$ & $(-0.72)$ & $(-0.72)$ & $(-0.70)$ & $(-1.15)$ \\
B + M + Year FE & -0.005 & -0.004 & -0.002 & -0.002 & -0.002 & -0.005 \\
& $(-1.27)$ & $(-0.81)$ & $(-0.39)$ & $(-0.38)$ & $(-0.37)$ & $(-0.87)$ \\
\hline
\end{tabular}

t statistics in parentheses; $+p<0.10,{ }^{*} p<0.05,{ }^{* *} p<0.01, * * * p<0.001$

Overall, estimation results are ambiguous and statistical relations are mostly insignificant. The data does not support the hypothesis that income inequality affects altruism in a significant way.

\section{Tolerance}

Tolerance implies respect for diversity. Tolerant people who belong to a majority group feel a duty of treating minority members (e.g. immigrants and homosexuals) in a fair way, i.e. as if they were treating other majority individuals. As pointed out by Corneo and Jeanne (2009), tolerance can be usefully interpreted as a characteristic of an individual's value system, rather than the evaluation of a special class of actions. A person can be seen as tolerant if she attaches symbolic value not only to her own characteristics but also to those that others have. Conversely, an intolerant person is complacent and disrespectful of traits and lifestyles that are not like hers. Thus, tolerance can be defined both for persons who are in the majority group and for persons who belong to a minority group.

Tolerance is likely to promote peaceful coexistence between diverse groups and to favor the manifestation of individual proclivities. Both effects are likely to be beneficial for macroeconomic performance since tolerance towards, say, different ethnicities, facilitates 
cooperation in firms and markets, and acceptance of individuality favors the development of talents and therefore the generation of innovations that may eventually fuel economic growth. However, tolerance may also contribute to the erosion of social norms that are good for the economy. Increased tolerance may imply that there is less social stigmatization of uncooperative or even criminal behavior, e.g. pretending of being sick so as to keep receiving one's wage without having to work for it. In such cases, more tolerant values may encourage the violation of norms of cooperation and harm the economy. Thus, the overall effect of tolerance on macroeconomic performance is a priori ambiguous.

In our dataset, tolerance is an element in a list of eleven qualities from which respondents can choose up to five. The survey question is the one already used above and it reads:

Here is a list of qualities that children can be encouraged to learn at home. Which, if any, do you consider to be especially important? Please choose up to five.

Tolerance; 0 'Not mentioned' 1 'Important'. 23

The observed combination of average tolerance and average income inequality across countries is shown in Figure 13.

Figure 13. Income inequality and child-tolerance across OECD-countries.

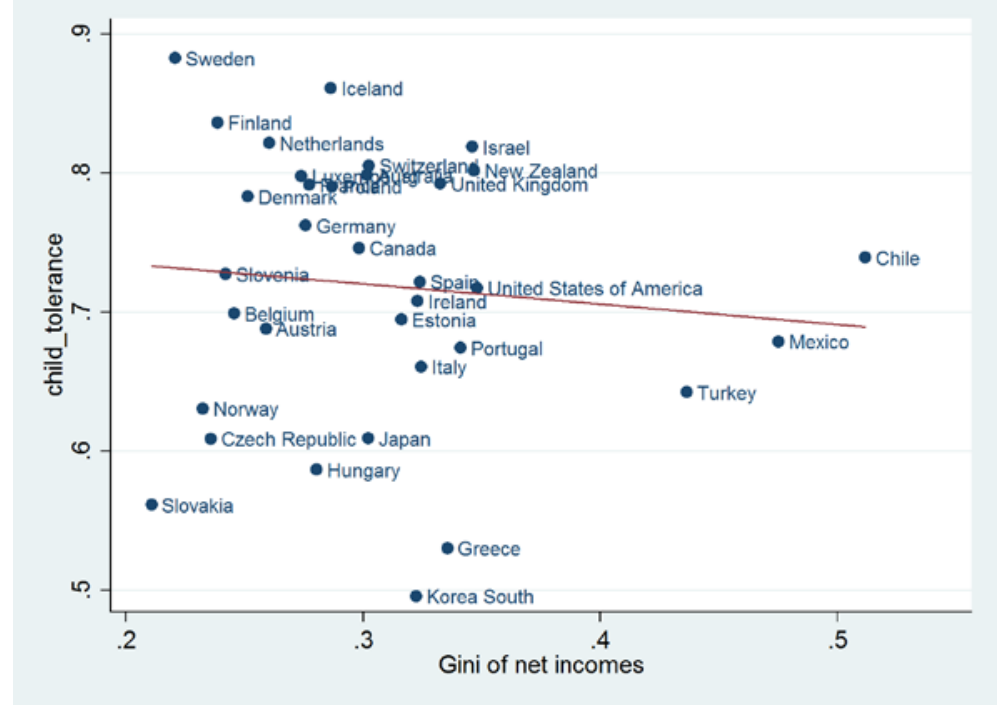

As shown by Table 25, if one controls for more individual characteristics than gender and age, there is an overwhelmingly negative association between the current Gini coefficient of

\footnotetext{
${ }^{23}$ This survey question has been used by Aghion et al. (2010) to construct a measure of civic education and by Tabellini (2007) to construct a measure of morality. See also Balan and Knack (2011), Dobler (2009), Gorodnichenko and Roland (2011), and Maystre et al. (2009).
} 
the income distribution and the probability that a respondent finds it important to teach their children the value of tolerance. In a few regressions, the effect from inequality is statistically significant at conventional levels.

Table 25. Coefficients of contemporaneous Gini for child-tolerance

\begin{tabular}{c|cccccc}
\hline & $(1)$ & $(2)$ & $(3)$ & $(4)$ & $(5)$ & $(6)$ \\
\hline Basic & $0.060^{*}$ & -0.029 & -0.028 & -0.032 & -0.030 & $-0.077^{*}$ \\
& $(2.08)$ & $(-0.82)$ & $(-0.72)$ & $(-0.78)$ & $(-0.74)$ & $(-2.47)$ \\
B + Macro & 0.023 & -0.007 & -0.003 & -0.018 & -0.016 & $-0.073^{+}$ \\
& $(0.72)$ & $(-0.18)$ & $(-0.08)$ & $(-0.41)$ & $(-0.37)$ & $(-1.79)$ \\
B + M + Year FE & 0.009 & $-0.058^{* *}$ & $-0.078^{* * *}$ & $-0.067^{* *}$ & $-0.067^{* *}$ & -0.023 \\
& $(0.33)$ & $(-2.65)$ & $(-3.57)$ & $(-3.15)$ & $(-3.08)$ & $(-0.79)$ \\
\hline
\end{tabular}

$t$ statistics in parentheses; $+p<0.10, * p<0.05,{ }^{* *} p<0.01, * * * p<0.001$

Table 26 reports our results on the effect produced by the experience of inequality during youth. In this case, income inequality systematically entertains a negative relation with childtolerance. The estimated coefficients are sometimes significant.

Table 26. Coefficients of Gini when aged 18-25 for child-tolerance

\begin{tabular}{c|cccccc}
\hline & $(1)$ & $(2)$ & $(3)$ & $(4)$ & $(5)$ & $(6)$ \\
\hline Basic & -0.003 & $-0.009^{+}$ & $-0.010^{+}$ & $-0.009^{+}$ & -0.008 & -0.008 \\
& $(-0.32)$ & $(-1.91)$ & $(-1.94)$ & $(-1.73)$ & $(-1.52)$ & $(-1.19)$ \\
B + Macro & $-0.012^{* *}$ & $-0.009^{+}$ & $-0.010^{+}$ & $-0.009^{+}$ & -0.008 & -0.009 \\
& $(-2.59)$ & $(-1.75)$ & $(-1.85)$ & $(-1.72)$ & $(-1.44)$ & $(-1.01)$ \\
B + M + Year FE & $-0.010^{*}$ & -0.007 & -0.009 & -0.008 & -0.007 & -0.005 \\
& $(-2.29)$ & $(-1.46)$ & $(-1.64)$ & $(-1.60)$ & $(-1.36)$ & $(-0.65)$ \\
\hline
\end{tabular}

t statistics in parentheses; $+p<0.10, * p<0.05,{ }^{* *} p<0.01,{ }^{* * *} p<0.001$

All in all, higher levels of income inequality seem to reduce tolerance. Comparing tolerance with the dimensions of value systems investigated in the previous sections shows that the evidence in support of a cultural effect of inequality is stronger than in the cases of civism, obedience, honesty, and altruism. However, the evidence concerning the effect on tolerance is not as strong as the one concerning the effect on the work ethic.

\section{Concluding Discussion}

This study has exploited attitudinal data from the WVS to explore the effect of income inequality on the dynamics of value systems. Six dimensions of value systems have been investigated: work ethic, civism, obedience, honesty, altruism, and tolerance. Results from a large number of regressions do not indicate that income inequality, as measured by the Gini coefficient of net household income, is a universal and important determinant of how values evolve. Thus, if income inequality affects outcomes, it seems to do so mainly through its 
effect on the budget constraints faced by households. However, we have also found that the evolution of inequality can contribute to explain value change in an important case.

Specifically, estimation results about civism substantially vary with the proxy that one uses to measure the subjective importance attributed to civic virtues. No systematic regularity could be detected in the relationship between altruism and inequality. The same applies to honesty. There is some weak evidence that the taste for obedience tends to increase with increasing inequality of net incomes, but this only applies to one of two employed proxies. Income inequality seems also to decrease the tolerance of the population, but only in the sense that individuals who experienced more inequality when young tend to have a less tolerant attitude.

The only robust finding of an effect of income inequality on values concerns the work ethic. We find that an increase of income disparities tends to be associated with a stronger work ethic, and this holds true for all four proxies employed in this investigation. The strongest effect refers to the one from the within-country variation in income inequality on the work ethic reported by individuals in the same country. Inequality experienced during youth also has a positive effect on the self-reported work ethic, but the evidence on that effect is weaker.

Thus, our main empirical finding suggests that income inequality generates work incentives not only through pay differentials - the material reward of hard working - but also through esteem differentials - the symbolic reward of hard working. As pointed out above, the economic implications of a stronger emphasis on hard work are a priori ambiguous. Existing evidence suggests that a stronger work ethic may improve economic performance if the work ethic is weak and may worsen economic performance if the work ethic is already strong.

A few qualifications are in order. The measures of values employed in this paper capture only some aspects of the values we are interested in and suffer from the usual limitations of attitudinal survey-based data. Furthermore, caution is needed because of well-known problems of comparability of inequality measures over time and across countries. These caveats notwithstanding, our finding that a growing income inequality contributes to explain a stronger work ethic endorsed by individuals has survived a number of robustness checks. Therefore, it may merit an in-depth theoretical and empirical analysis so as to identify the precise mechanisms behind the relationship between income inequality and work ethic. While such an analysis is beyond the scope of the current paper, we close with two remarks about the possible origin of that relationship and its implications. 
First, one may use the modeling approach sketched in Section 2 to explain how income inequality may bring about value systems that put more emphasis on hard work. That theoretical framework suggests that a stronger work ethic may result from purposive value formation to achieve a high level of self-esteem. A natural interpretation of why a more unequal income distribution would make emphasis on hard work more valuable in order to secure self-esteem is that an increased income inequality ex post usually means an increased income uncertainty ex ante. While individual income has a large random component, work effort can often be controlled by individuals. Thus, in an economy with large income disparities it is difficult to predict one's income level, but one can be rather sure that one will be a hard working person if a strong work ethic was instilled. In analogy with portfolio theory, the increased uncertainty about individual income may make families shift symbolic value from being economically successful to being laborious, so as to secure at least some minimal level of self-esteem for their members.

Second, there is an interesting implication of the effect of income inequality on the work ethic, namely that it may be self-reinforcing in some circumstances. A stronger emphasis on hard work increases individual and aggregate labor supply, thereby reducing the price of labor relative to the price of capital. Since capital income generates a larger share of the income of households in the top fractiles of the income distribution than in the remaining quantiles, that change in factor prices may further increase income inequality. In that case, inequality may keep growing and, since value change is a slow-moving process, the inequality increase may be long-lived. 


\section{References}

Aghion, P., Algan Y., Cahuc, P. and A. Shleifer, 2010. Regulation and Distrust. The Quarterly Journal of Economics, 125(3), 1015-1049.

Akerlof, G. A., 1983, Loyalty filters. American Economic Review 73, 54-63.

Akerlof, G. A. and R. E. Kranton, 2000. Economics and Identity. The Quarterly Journal of Economics, vol. 115(3), 715-753.

Akerlof, G. A. and R. E. Kranton, 2005. Identity and the Economics of Organizations. Journal of Economic Perspectives, 19, 715-53.

Algan, Y. and P. Cahuc, 2009. Civic Virtue and Labor Market Institutions. American Economic Journal: Macroeconomics, 1(1), 111-145.

Atkinson, A. B. and A. Brandolini, 2001. Promise and Pitfalls in the Use of "Secondary" Data-Sets: Income Inequality in OECD Countries, Journal of Economic Literature 34, 771799.

Auriol, E. and R. Renault, 2008, Status and incentives, RAND Journal of Economics 39, 305326.

Balan, D. J. and S. Knack, 2011. The Correlation between Human Capital and Morality and its Effect on Economic Performance: Theory and Evidence. Revised and Resubmitted to the Journal of Comparative Economics.

Berry, H., Guillén, M., and N. Zhou, 2010. A new approach to cross-national distance. (Working Paper). Philadelphia, PA: Wharton School of Business.

Bisin, A. and T. Verdier, 2000. Beyond the Melting Pot: Cultural Transmission, Marriage and the Evolution of Ethnic and Religious Traits, Quarterly Journal of Economics, 115, 955-88.

Bisin, A. and T. Verdier, 2001. The Economics of Cultural Transmission and the Dynamics of Preferences, Journal of Economic Theory, 97, 298-319.

Corneo, G., 2011. Income inequality, value systems, and macroeconomic performance, Amsterdam, AIAS, GINI Discussion Paper 17.

Corneo, G., 2012. Work norms and the welfare state, CESifo Economic Studies, forthcoming.

Corneo, G. and O. Jeanne, 2009. A theory of tolerance, Journal of Public Economics 93, 691702.

Corneo, G. and O. Jeanne, 2010. Symbolic values, occupational choice, and economic development. European Economic Review 54, 241-255.

Doepke, M. and F. Zilibotti, 2008. Occupational choice and the spirit of capitalism, Quarterly Journal of Economics 123, 747-793. 
Deininger, K. and L. Squire, 1996. A New Data Set Measuring Income Inequality, World Bank Economic Review, 10(3), 565-91.

Di Tella, R. and J. Dubra, 2010. Peronist Beliefs and Interventionist Policies, NBER Working Papers 16621, National Bureau of Economic Research.

Dobler, C., 2009. The impact of institutions, culture, and religion on per capita income. Discussion paper Nr. 28, Evangelisches Studienwerk e.V. Villigst, Oldenburg.

Fehr, E. and K. Hoff, 2011. Introduction: Tastes, Castes and Culture: the Influence of Society on Preferences, The Economic Journal 121, F396-F412.

Giuliano, P. and A. Spilimbergo, 2009. Growing Up in a Recession: Beliefs and the Macroeconomy, NBER Working Papers 15321, National Bureau of Economic Research, Inc.

Gorodnichenko, Y. and G. Roland, 2011. Which Dimensions of Culture Matter for Long run Growth, Mimeo, Berkeley University.

Gradstein, M., 2009. Work Attitudes and Intergenerational Mobility, Journal of Human Capital 3 (3), 268-288.

Guiso, L., Sapienza, P. and L. Zingales, 2010. Civic Capital as the Missing Link, NBER Working Paper 15845, National Bureau of Economic Research, Inc.

Halla, M., Lackner, M. and F. Schneider, 2010. An Empirical Analysis of the Dynamics of the Welfare State: The Case of Benefit Morale, Kyklos 63(1), 55-74.

Heinemann, F., 2008. Is the Welfare State Self-Destructive? A Study of Government Benefit Morale, Kyklos, 61(2), 237-257.

Inglehart, R. F. and W. Baker, 2000. Modernization, cultural change, and the persistence of traditional values. American Sociological Review 65, 19-51.

Inglehart, R. F., and Ch. Welzel, 2005. Modernization, cultural change, and democracy : the human development sequence. New York : Cambridge University Press.

Knack, S. and P. Keefer, 1997. Does social capital have an economic payoff? A cross-country investigation. Quarterly Journal of Economics 112 (4), 1251-1288.

Lindbeck, A. and S. Nyberg, 2006. Raising Children to Work Hard: Altruism, Work Norms, and Social Insurance. The Quarterly Journal of Economics, 121(4), 1473-1503.

Maystre, N., Jacques, O., Thoenig, M. and T. Verdier, 2009. Product-Based Cultural Change: Is the Village Global?, CEPR Discussion Papers 7438.

Milanovic, B., 2011. Global inequality recalculated and updated: The effect of new PPP estimates on global inequality and 2005 estimates. Journal of Economic Inequality,1, 1-18.

Minkov, M. and V. Blagoev, 2009. Cultural Values Predict Subsequent Economic Growth. International Journal of Cross Cultural Management, 9-1, 5-24. 
Moulton, B., 1990. An Illustration of a Pitfall in Estimating the Effects of Aggregate Variables on Micro Unit. Review of Economics and Statistics 72, 334-338.

Neher, F., 2012. Essays on Aspects of Culture in Economics. mimeo.

OECD, 2008. Growing Unequal? Income Distribution and Poverty in OECD Countries. OECD Publishing.

OECD, 2011. Divided We Stand: Why Inequality Keeps Rising. OECD Publishing.

Östling, R., 2009. Economic Influences on Moral Values. The B.E. Journal of Economic Analysis \& Policy 9, 1.

Schaltegger, Ch. A. and B. Torgler, 2009. Work Ethic, Protestantism, and Human Capital. Economics Letters 107, 99-101.

Schneider, S. and B. Torgler, 2006. What Shapes Attitudes Toward Paying Taxes? Evidence from Multicultural European Countries, IZA Discussion Papers 2117, Institute for the Study of Labor.

Solt, F., 2009. Standardizing the World Income Inequality Database. Social Science Quarterly 90, 231-242.

Tabellini, G., 2007. Culture and institutions. DP 6589, CEPR.

Tabellini, G., 2008, The scope of cooperation: Values and incentives, Quarterly Journal of Economics 123, 905-950.

Wilkinson, R. and K. Pickett, 2009. The Spirit Level. Bloomsbury Press: London.

You, J. and S. Khagram, 2005. A comparative study of inequality and corruption. American Sociological Review 70, 136-157. 
Table A1. Mean of work-first by country and wave.

\begin{tabular}{|c|c|c|c|c|}
\hline Country & 4 & 5 & 6 & Total \\
\hline Australia & . & 2.628 & . & 2.628 \\
\hline Austria & & . & 3.415 & 3.415 \\
\hline Belgium & 2.825 & . & 2.854 & 2.838 \\
\hline Canada & 3.138 & 2.803 & . & 2.962 \\
\hline Chile & 3.375 & 3.478 & & 3.422 \\
\hline Czech Republic & 3.464 & . & 3.374 & 3.420 \\
\hline Denmark & 3.249 & . & 3.249 & 3.249 \\
\hline Estonia & 3.221 & 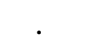 & 3.070 & 3.128 \\
\hline Finland & 2.939 & 2.929 & 2.719 & 2.859 \\
\hline France & 2.755 & . & 2.944 & 2.846 \\
\hline Germany & 3.465 & 3.679 & 3.576 & 3.574 \\
\hline Greece & 2.989 & . & 3.522 & 3.293 \\
\hline Hungary & 4.093 & . & 3.641 & 3.820 \\
\hline Iceland & 2.830 & . & 2.636 & 2.742 \\
\hline Ireland & 2.913 & . & 3.045 & 2.978 \\
\hline Israel & 3.887 & 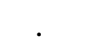 & & 3.887 \\
\hline Italy & 3.294 & 3.337 & 3.230 & 3.282 \\
\hline Japan & 2.644 & 2.749 & . & 2.691 \\
\hline Korea & 3.019 & 3.143 & . & 3.081 \\
\hline Luxembourg & 2.962 & & 3.164 & 3.078 \\
\hline Mexico & 3.678 & 3.432 & & 3.553 \\
\hline Netherlands & 2.481 & . & 2.779 & 2.661 \\
\hline New Zealand & 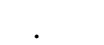 & . & . & . \\
\hline Norway & 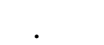 & 3.179 & 3.147 & 3.163 \\
\hline Poland & 3.709 & 3.589 & 3.077 & 3.413 \\
\hline Portugal & 3.119 & . & 3.534 & 3.372 \\
\hline Slovakia & 3.639 & . & 3.718 & 3.681 \\
\hline Slovenia & 3.445 & 3.347 & 3.258 & 3.340 \\
\hline Spain & 3.289 & 3.233 & 3.337 & 3.290 \\
\hline Sweden & 2.720 & 2.870 & 3.007 & 2.833 \\
\hline Switzerland & & 3.214 & 3.123 & 3.168 \\
\hline Turkey & 3.791 & 3.781 & 4.008 & 3.890 \\
\hline UK & 2.631 & & 2.890 & 2.788 \\
\hline USA & 2.907 & 2.847 & . & 2.876 \\
\hline Total & 3.188 & 3.192 & 3.257 & 3.215 \\
\hline
\end{tabular}

Table A2. Mean of money-work by country and wave

\begin{tabular}{|c|c|c|c|c|}
\hline country & 4 & 5 & 6 & Total \\
\hline Australia & . & 3.283 & & 3.283 \\
\hline Austria & . & . & 3.365 & 3.365 \\
\hline Belgium & 3.070 & . & 3.086 & 3.077 \\
\hline Canada & 3.306 & 3.150 & . & 3.224 \\
\hline Chile & 3.681 & 3.489 & & 3.594 \\
\hline
\end{tabular}




\begin{tabular}{c|cccc}
\hline Czech Republic & 3.326 &. & 3.402 & 3.363 \\
Denmark & 2.888 &. & 2.771 & 2.818 \\
Estonia & 3.390 &. & 3.487 & 3.449 \\
Finland & 3.084 & 3.105 & 3.080 & 3.089 \\
France & 3.093 &. & 3.151 & 3.121 \\
Germany & 3.011 & 3.143 & 3.420 & 3.192 \\
Greece & 3.531 &. & 3.776 & 3.670 \\
Hungary & 3.484 &. & 3.544 & 3.521 \\
Iceland & 3.090 &. & 2.910 & 3.008 \\
Ireland & 3.248 &. & 3.419 & 3.332 \\
Israel & 3.710 &. &. & 3.710 \\
Italy & 3.807 & 3.663 & 3.762 & 3.759 \\
Japan & 3.380 & 3.367 &. & 3.374 \\
Korea & 3.793 & 3.649 &. & 3.720 \\
Luxembourg & 3.453 &. & 3.509 & 3.485 \\
Mexico & 3.344 & 3.255 &. & 3.299 \\
Netherlands & 2.643 &. & 2.952 & 2.830 \\
New Zealand &. &. &. &. \\
Norway &. & 3.356 & 3.216 & 3.286 \\
Poland & 3.719 & 3.596 & 3.356 & 3.533 \\
Portugal & 3.427 &. & 3.698 & 3.592 \\
Slovakia & 3.474 &. & 3.465 & 3.470 \\
Slovenia & 3.453 & 3.284 & 3.320 & 3.348 \\
Spain & 3.210 & 3.142 & 2.963 & 3.121 \\
Sweden & 3.038 & 2.893 & 3.176 & 3.039 \\
Switzerland &. & 3.209 & 3.024 & 3.116 \\
Turkey & 4.242 & 4.270 & 4.292 & 4.273 \\
UK & 3.017 &. & 3.248 & 3.157 \\
USA & 3.023 & 3.287 &. & 3.157 \\
& & & & \\
\hline Total & 3.334 & 3.348 & 3.372 & 3.351 \\
\hline & & & &
\end{tabular}

Table A3. Mean of work-duty by country and wave.

\begin{tabular}{c|cccc}
\hline country & 4 & 5 & 6 & Total \\
\hline Australia & & & & \\
Austria &. & 3.491 &. & 3.491 \\
Belgium &. &. & 3.888 & 3.888 \\
Canada & 3.622 & 3.623 &. & 3.648 \\
Chile & 3.807 & 3.964 &. & 3.879 \\
Czech Republic & 3.645 &. & 3.499 & 3.575 \\
Denmark & 3.750 &. & 3.991 & 3.895 \\
Estonia & 3.505 &. & 3.480 & 3.489 \\
Finland & 3.486 & 3.643 & 3.503 & 3.543 \\
France & 3.455 &. & 3.858 & 3.649 \\
Germany & 3.576 & 3.749 & 3.762 & 3.696 \\
Greece & 3.320 &. & 3.738 & 3.559 \\
Hungary & 3.830 &. & 3.788 & 3.804 \\
Iceland & 3.435 &. & 3.411 & 3.424 \\
Ireland & 3.538 &. & 3.753 & 3.644 \\
Israel & 3.913 &. &. & 3.913 \\
Italy & 3.760 & 3.802 & 3.826 & 3.791 \\
Japan & 3.640 & 3.726 &. & 3.679 \\
\hline
\end{tabular}




\begin{tabular}{c|cccc}
\hline Korea & 3.666 & 3.723 &. & 3.695 \\
Luxembourg & 3.803 &. & 4.066 & 3.955 \\
Mexico & 3.876 & 3.953 &. & 3.916 \\
Netherlands & 3.387 &. & 3.731 & 3.596 \\
New Zealand & $\cdot$ &. &. &. \\
Norway &. & 4.082 & 4.211 & 4.146 \\
Poland & 3.930 & 3.792 & 3.328 & 3.642 \\
Portugal & 4.143 &. & 4.117 & 4.127 \\
Slovakia & 3.682 &. & 3.680 & 3.681 \\
Slovenia & 3.934 & 3.924 & 3.875 & 3.907 \\
Spain & 3.598 & 3.703 & 3.628 & 3.632 \\
Sweden & 3.456 & 3.536 & 3.660 & 3.529 \\
Switzerland &. & 3.710 & 3.784 & 3.747 \\
Turkey & 4.284 & 4.208 & 4.225 & 4.235 \\
UK & 3.290 &. & 3.696 & 3.537 \\
USA & 3.474 & 3.522 &. & 3.498 \\
& & & & \\
\hline Total & 3.660 & 3.766 & 3.788 & 3.731 \\
\hline
\end{tabular}

Table A4. Mean of child-hardwork by country and wave.

\begin{tabular}{|c|c|c|c|c|c|c|c|}
\hline country & 1 & 2 & 3 & 4 & 5 & 6 & Total \\
\hline Australia & 0.119 & . & 0.359 & . & 0.477 & . & 0.332 \\
\hline Austria & . & 0.143 & . & 0.090 & . & 0.129 & 0.120 \\
\hline Belgium & 0.325 & 0.343 & . & 0.425 & . & 0.367 & 0.367 \\
\hline Canada & 0.202 & 0.350 & . & 0.506 & 0.526 & . & 0.420 \\
\hline Chile & . & 0.120 & 0.166 & 0.256 & 0.258 & . & 0.194 \\
\hline Czech Republic & . & 0.838 & 0.789 & 0.739 & . & 0.740 & 0.785 \\
\hline Denmark & 0.021 & 0.024 & . & 0.021 & . & 0.045 & 0.029 \\
\hline Estonia & . & 0.920 & 0.871 & 0.812 & . & 0.828 & 0.854 \\
\hline Finland & . & 0.059 & 0.147 & 0.115 & 0.153 & 0.076 & 0.114 \\
\hline France & 0.334 & 0.529 & . & 0.504 & 0.623 & 0.489 & 0.491 \\
\hline Germany & . & 0.149 & 0.099 & 0.226 & 0.275 & 0.171 & 0.180 \\
\hline Greece & . & . & . & 0.313 & . & 0.289 & 0.300 \\
\hline Hungary & 0.285 & 0.704 & 0.337 & 0.714 & . & 0.759 & 0.569 \\
\hline Iceland & 0.239 & 0.779 & . & 0.443 & . & 0.456 & 0.460 \\
\hline Ireland & 0.235 & 0.276 & . & 0.365 & . & 0.601 & 0.346 \\
\hline Israel & . & . & . & 0.242 & . & . & 0.242 \\
\hline Italy & 0.128 & 0.236 & . & 0.361 & 0.393 & 0.388 & 0.298 \\
\hline Japan & 0.154 & 0.306 & 0.244 & 0.271 & 0.324 & . & 0.258 \\
\hline Korea & 0.400 & 0.643 & 0.622 & 0.716 & 0.727 & . & 0.630 \\
\hline Luxembourg & . & . & . & 0.572 & . & 0.511 & 0.537 \\
\hline Mexico & . & 0.233 & 0.360 & 0.287 & 0.243 & . & 0.290 \\
\hline Netherlands & 0.118 & 0.138 & . & 0.137 & 0.294 & 0.210 & 0.181 \\
\hline New Zealand & . & . & 0.372 & . & 0.407 & . & 0.387 \\
\hline Norway & 0.038 & 0.066 & 0.107 & . & 0.127 & 0.113 & 0.089 \\
\hline Poland & . & 0.867 & 0.160 & 0.864 & 0.211 & 0.826 & 0.597 \\
\hline Portugal & . & 0.691 & . & 0.672 & . & 0.695 & 0.687 \\
\hline Slovakia & . & 0.831 & 0.703 & 0.753 & . & 0.859 & 0.794 \\
\hline Slovenia & . & 0.320 & 0.329 & 0.292 & 0.338 & 0.325 & 0.321 \\
\hline Spain & 0.405 & 0.367 & 0.644 & 0.451 & 0.626 & 0.206 & 0.421 \\
\hline Sweden & 0.038 & 0.052 & 0.066 & 0.041 & 0.102 & 0.095 & 0.063 \\
\hline Switzerland & . & 0.375 & 0.431 & . & 0.266 & 0.258 & 0.333 \\
\hline
\end{tabular}




\begin{tabular}{c|ccccccc}
\hline Turkey & $\cdot$ & 0.725 & 0.616 & 0.724 & 0.787 & $\cdot$ & 0.758 \\
UK & 0.149 & 0.282 & 0.371 & 0.378 & 0.443 & 0.442 & 0.344 \\
USA & 0.263 & 0.489 & 0.534 & 0.596 & 0.616 & $\cdot$ & 0.468 \\
& & & & & & & \\
Total & 0.217 & 0.402 & 0.397 & 0.444 & 0.400 & 0.447 & 0.398 \\
\hline
\end{tabular}

Table A5. Mean of justify-govbenefit by country and wave.

\begin{tabular}{|c|c|c|c|c|c|c|c|}
\hline country & 1 & 2 & 3 & 4 & 5 & 6 & Total \\
\hline Australia & 9.206 & . & 9.294 & . & 9.246 & . & 9.257 \\
\hline Austria & . & 9.343 & . & 8.908 & . & 8.505 & 8.915 \\
\hline Belgium & 8.879 & 8.381 & . & 8.451 & . & 8.916 & 8.585 \\
\hline Canada & 8.573 & 9.112 & . & 9.120 & 9.134 & . & 9.025 \\
\hline Chile & . & 6.941 & 7.645 & 7.669 & 6.778 & . & 7.244 \\
\hline Czech Republic & . & 7.188 & 8.207 & 9.194 & . & 8.626 & 8.145 \\
\hline Denmark & 9.644 & 9.520 & . & 9.619 & . & 9.624 & 9.606 \\
\hline Estonia & . & 8.719 & 8.828 & 7.801 & . & 8.388 & 8.430 \\
\hline Finland & . & 6.258 & 8.976 & 8.653 & 8.927 & 9.119 & 8.608 \\
\hline France & 7.567 & 7.533 & . & 7.621 & 7.848 & 7.366 & 7.572 \\
\hline Germany & . & 9.062 & 8.787 & 9.002 & 8.878 & 8.960 & 8.953 \\
\hline Greece & . & . & . & 6.964 & . & 6.879 & 6.915 \\
\hline Hungary & 9.467 & 8.191 & 8.239 & 9.359 & . & 9.414 & 9.070 \\
\hline Iceland & 9.335 & 9.228 & . & 9.248 & . & 9.501 & 9.328 \\
\hline Ireland & 9.133 & 9.061 & . & 9.171 & . & 8.976 & 9.088 \\
\hline Israel & . & . & . & . & . & . & . \\
\hline Italy & 9.533 & 8.924 & . & 9.118 & 9.383 & 9.166 & 9.182 \\
\hline Japan & 9.088 & 9.012 & 8.914 & 8.908 & 8.910 & . & 8.963 \\
\hline Korea & 8.888 & 8.797 & . & . & 8.366 & . & 8.668 \\
\hline Luxembourg & . & . & . & 8.131 & . & 7.898 & 7.997 \\
\hline Mexico & . & 6.076 & 7.699 & 7.283 & 6.906 & . & 7.076 \\
\hline Netherlands & 9.540 & 9.389 & . & 9.512 & 9.536 & 9.520 & 9.503 \\
\hline New Zealand & . & . & 9.132 & . & 9.147 & . & 9.138 \\
\hline Norway & 9.579 & 9.567 & 9.362 & . & 8.936 & 9.093 & 9.320 \\
\hline Poland & . & 8.874 & 8.705 & 8.638 & 8.684 & 8.198 & 8.626 \\
\hline Portugal & . & 8.201 & . & 8.946 & . & 8.901 & 8.690 \\
\hline Slovakia & . & 6.998 & 7.718 & 8.090 & . & 8.065 & 7.693 \\
\hline Slovenia & . & 8.192 & 7.620 & 8.180 & 7.996 & 8.405 & 8.100 \\
\hline Spain & 8.647 & 8.425 & 9.078 & 8.617 & 8.473 & 8.334 & 8.556 \\
\hline Sweden & 9.569 & 9.372 & 8.848 & 8.919 & 9.129 & 9.061 & 9.113 \\
\hline Switzerland & . & 9.082 & 8.669 & . & 9.417 & 9.262 & 9.112 \\
\hline Turkey & . & 9.477 & . & 9.761 & 9.394 & 9.628 & 9.575 \\
\hline UK & 9.175 & 9.177 & . & 9.027 & 8.837 & 9.445 & 9.164 \\
\hline USA & 9.267 & 9.057 & 9.374 & 8.831 & 8.818 & . & 9.108 \\
\hline Total & 9.108 & 8.500 & 8.636 & 8.683 & 8.721 & 8.764 & 8.704 \\
\hline
\end{tabular}

Table A6. Mean of justify-nofare by country and wave.

\begin{tabular}{c|cccccccc}
\hline country & \multicolumn{1}{|c}{2} & 2 & 3 & 4 & 5 & 6 & Total \\
\hline & & & & & & & \\
Australia & 8.635 &. & 8.922 &. & 8.665 &. & 8.770 \\
Austria &. & 9.131 &. & 8.739 &. & 8.126 & 8.661 \\
\hline
\end{tabular}




\begin{tabular}{|c|c|c|c|c|c|c|c|}
\hline Belgium & 8.834 & 8.541 & . & 8.608 & . & 8.528 & 8.599 \\
\hline Canada & 8.656 & 8.874 & . & 8.770 & 8.778 & . & 8.778 \\
\hline Chile & . & 7.857 & 8.374 & 7.578 & 7.163 & . & 7.752 \\
\hline Czech Republic & . & 8.875 & 7.794 & 8.048 & . & 7.830 & 8.204 \\
\hline Denmark & 9.223 & 9.244 & . & 9.228 & . & 9.143 & 9.203 \\
\hline Estonia & . & 8.716 & 7.974 & . & . & 8.623 & 8.465 \\
\hline Finland & . & 8.782 & 8.692 & 8.502 & 8.723 & 8.379 & 8.596 \\
\hline France & 8.338 & 8.376 & . & 8.324 & 8.158 & 8.490 & 8.348 \\
\hline Germany & . & 8.922 & 7.888 & 9.043 & 8.780 & 8.594 & 8.679 \\
\hline Greece & . & . & . & 7.567 & . & 8.515 & 8.114 \\
\hline Hungary & 9.309 & 7.718 & 7.230 & . & . & 8.249 & 8.325 \\
\hline Iceland & 8.647 & 8.149 & . & . & . & 8.276 & 8.380 \\
\hline Ireland & 8.440 & 8.762 & . & . & . & 8.062 & 8.428 \\
\hline Israel & . & . & . & . & . & . & . \\
\hline Italy & 9.207 & 8.906 & . & 8.832 & 8.906 & 8.678 & 8.895 \\
\hline Japan & 9.406 & 9.476 & 9.438 & 9.377 & 9.419 & . & 9.420 \\
\hline Korea & 8.923 & 8.229 & 8.357 & 8.254 & 8.211 & . & 8.370 \\
\hline Luxembourg & . & . & . & 8.340 & . & 8.210 & 8.265 \\
\hline Mexico & . & 6.796 & 7.641 & 7.208 & 6.687 & . & 7.146 \\
\hline Netherlands & 8.540 & 8.767 & . & 8.236 & 8.982 & 8.622 & 8.629 \\
\hline New Zealand & . & . & 8.953 & . & 8.941 & . & 8.948 \\
\hline Norway & 9.449 & 9.300 & 9.066 & . & 8.716 & 8.732 & 9.064 \\
\hline Poland & . & 9.124 & 9.035 & . & 8.502 & 8.019 & 8.615 \\
\hline Portugal & . & 8.134 & . & . & . & 8.986 & 8.618 \\
\hline Slovakia & . & 8.232 & 7.388 & . & . & 7.808 & 7.813 \\
\hline Slovenia & . & 8.504 & 8.246 & . & 7.779 & 8.632 & 8.322 \\
\hline Spain & 8.541 & 8.652 & 9.034 & 8.778 & 8.594 & 8.071 & 8.602 \\
\hline Sweden & 9.395 & 9.014 & 8.115 & . & 8.269 & 7.778 & 8.491 \\
\hline Switzerland & . & 9.301 & 8.717 & . & 9.195 & 8.834 & 9.021 \\
\hline Turkey & . & 9.040 & . & . & 9.145 & 9.614 & 9.353 \\
\hline UK & 8.750 & 8.929 & . & 8.368 & 8.618 & 8.684 & 8.694 \\
\hline USA & 9.015 & 8.841 & 9.128 & 8.357 & 8.556 & . & 8.830 \\
\hline Total & 8.887 & 8.672 & 8.424 & 8.458 & 8.522 & 8.495 & 8.574 \\
\hline
\end{tabular}

Table A7. Mean of justify-taxcheat by country and wave.

\begin{tabular}{c|cccccccc}
\hline country & \multicolumn{2}{c}{1} & \multicolumn{2}{c}{3} & 4 & 5 & 6 & Total \\
\hline & & & & & & & \\
Australia & 7.927 &. & 8.843 &. & 8.965 &. & 8.641 \\
Austria &. & 9.026 &. & 8.900 &. & 8.435 & 8.785 \\
Belgium & 7.679 & 6.894 &. & 7.389 &. & 7.814 & 7.332 \\
Canada & 8.756 & 8.600 &. & 8.984 & 9.186 &. & 8.911 \\
Chile &. & 9.139 & 8.834 & 8.831 & 9.045 &. & 8.976 \\
Czech Republic &. & 9.185 & 8.020 & 8.977 &. & 8.515 & 8.768 \\
Denmark & 8.489 & 8.555 &. & 8.995 &. & 9.188 & 8.835 \\
Estonia &. & 8.920 & 7.627 & 7.824 &. & 8.723 & 8.327 \\
Finland &. & 7.843 & 8.433 & 8.454 & 8.858 & 9.072 & 8.603 \\
France & 7.555 & 7.918 &. & 7.965 & 8.176 & 8.530 & 8.049 \\
Germany &. & 8.435 & 8.014 & 8.629 & 8.861 & 9.028 & 8.576 \\
Greece &. &. &. & 7.843 &. & 8.585 & 8.271 \\
Hungary &. & 7.907 & 8.598 & 8.915 &. & 9.369 & 8.793 \\
Iceland & 8.467 & 8.447 &. & 8.773 &. & 9.024 & 8.683 \\
Ireland & 7.623 & 8.259 &. & 8.710 &. & 8.684 & 8.286 \\
Israel &. &. &. &. &. &. &. \\
\hline
\end{tabular}




\begin{tabular}{c|ccccccc}
\hline Italy & 9.094 & 8.466 &. & 8.608 & 8.824 & 8.746 & 8.708 \\
Japan & 9.522 & 9.520 & 9.491 & 9.537 & 9.544 &. & 9.524 \\
Korea & 9.444 & 9.453 & 9.213 & 9.409 & 9.336 &. & 9.367 \\
Luxembourg &. &. &. & 7.650 &. & 8.308 & 8.029 \\
Mexico &. & 7.199 & 7.918 & 8.693 & 8.375 &. & 8.029 \\
Netherlands & 7.810 & 8.038 &. & 8.262 & 8.737 & 8.739 & 8.344 \\
New Zealand &. &. & 8.698 &. & 8.835 &. & 8.757 \\
Norway & 7.665 & 7.904 & 8.287 &. & 8.718 & 8.668 & 8.234 \\
Poland &. & 8.284 & 8.514 & 8.860 & 8.545 & 8.374 & 8.478 \\
Portugal &. & 7.182 &. & 8.564 &. & 8.855 & 8.247 \\
Slovakia &. & 8.873 & 7.740 & 8.852 &. & 8.669 & 8.561 \\
Slovenia &. & 8.971 & 8.185 & 8.663 & 8.630 & 9.015 & 8.714 \\
Spain & 8.148 & 8.392 & 9.082 & 8.750 & 8.937 & 8.574 & 8.555 \\
Sweden & 9.196 & 8.535 & 8.419 & 8.575 & 8.706 & 8.679 & 8.665 \\
Switzerland &. & 8.628 & 8.354 &. & 8.918 & 8.828 & 8.684 \\
Turkey &. & 9.755 &. & 9.820 & 9.661 & 9.713 & 9.730 \\
UK & 8.171 & 8.476 &. & 8.569 & 8.709 & 9.158 & 8.643 \\
USA & 8.880 & 9.052 & 9.316 & 8.777 & 9.045 &. & 9.011 \\
& & & & & & & \\
\hline Total & 8.402 & 8.437 & 8.492 & 8.643 & 8.908 & 8.789 & 8.615 \\
\hline
\end{tabular}

Table A8. Mean of justify-bribe by country and wave

\begin{tabular}{|c|c|c|c|c|c|c|c|}
\hline country & 1 & 2 & 3 & 4 & 5 & 6 & Total \\
\hline Australia & 9.325 & . & 9.731 & . & 9.518 & . & 9.561 \\
\hline Austria & . & 9.401 & . & 9.430 & . & 9.078 & 9.302 \\
\hline Belgium & 8.702 & 8.650 & . & 9.023 & . & 9.014 & 8.834 \\
\hline Canada & 9.340 & 9.384 & . & 9.449 & 9.454 & . & 9.416 \\
\hline Chile & . & 9.547 & 9.333 & 8.950 & 9.296 & . & 9.296 \\
\hline Czech Republic & . & 8.806 & 8.719 & 8.820 & . & 8.432 & 8.713 \\
\hline Denmark & 9.791 & 9.788 & . & 9.854 & . & 9.804 & 9.808 \\
\hline Estonia & . & 9.072 & 9.493 & 9.074 & . & 9.479 & 9.304 \\
\hline Finland & . & 9.431 & 9.587 & 9.560 & 9.402 & 9.722 & 9.553 \\
\hline France & 8.384 & 8.888 & . & 8.923 & 8.809 & 9.086 & 8.838 \\
\hline Germany & . & 9.080 & 9.087 & 9.065 & 9.291 & 9.152 & 9.129 \\
\hline Greece & . & . & . & 9.073 & . & 9.209 & 9.152 \\
\hline Hungary & 9.139 & 8.298 & 7.306 & 8.413 & . & 9.083 & 8.635 \\
\hline Iceland & 9.614 & 9.589 & . & 9.731 & . & 9.782 & 9.682 \\
\hline Ireland & 9.482 & 9.666 & . & 9.596 & . & 8.994 & 9.439 \\
\hline Israel & . & . & . & 9.575 & . & . & 9.575 \\
\hline Italy & 8.984 & 9.334 & . & 9.498 & 9.681 & 9.426 & 9.379 \\
\hline Japan & 9.126 & 9.211 & 9.421 & 9.472 & 9.460 & . & 9.345 \\
\hline Korea & 8.912 & 9.189 & 9.493 & 9.582 & 9.410 & . & 9.336 \\
\hline Luxembourg & . & . & . & 9.177 & . & 9.282 & 9.238 \\
\hline Mexico & . & 8.248 & 8.450 & 8.872 & 8.564 & . & 8.522 \\
\hline Netherlands & 8.990 & 9.215 & . & 9.436 & 9.448 & 9.527 & 9.333 \\
\hline New Zealand & . & . & 9.543 & . & 9.550 & . & 9.546 \\
\hline Norway & 9.651 & 9.541 & 9.679 & . & 9.481 & 9.590 & 9.589 \\
\hline Poland & . & 9.441 & 9.630 & 9.474 & 9.615 & 8.925 & 9.391 \\
\hline Portugal & . & 9.313 & . & 9.217 & . & 9.302 & 9.282 \\
\hline Slovakia & . & 8.517 & 8.384 & 8.076 & . & 8.508 & 8.382 \\
\hline Slovenia & . & 9.327 & 9.170 & 9.224 & 9.141 & 9.441 & 9.273 \\
\hline Spain & 9.418 & 9.522 & 9.581 & 9.346 & 9.181 & 9.504 & 9.441 \\
\hline
\end{tabular}




\begin{tabular}{c|ccccccc}
\hline Sweden & 9.400 & 9.363 & 9.205 & 9.149 & 9.016 & 8.936 & 9.169 \\
Switzerland & $\cdot$ & 9.407 & 9.412 & $\cdot$ & 9.481 & 9.474 & 9.443 \\
Turkey & $\cdot$ & 9.804 & $\cdot$ & 9.880 & 9.718 & 9.769 & 9.786 \\
UK & 9.294 & 9.485 & $\cdot$ & 9.220 & 9.347 & 9.568 & 9.405 \\
USA & 9.502 & 9.535 & 9.781 & 9.440 & 9.413 & $\cdot$ & 9.540 \\
& & & & & & & \\
\hline Total & 9.257 & 9.211 & 9.240 & 9.237 & 9.342 & 9.275 & 9.255 \\
\hline
\end{tabular}

Table A9. Mean of child-obedience by country and wave

\begin{tabular}{|c|c|c|c|c|c|c|c|}
\hline country & 1 & 2 & 3 & 4 & 5 & 6 & Total \\
\hline Australia & 0.411 & . & 0.287 & . & 0.366 & . & 0.343 \\
\hline Austria & . & 0.254 & . & 0.177 & . & 0.140 & 0.190 \\
\hline Belgium & 0.288 & 0.365 & . & 0.421 & . & 0.365 & 0.367 \\
\hline Canada & 0.210 & 0.282 & . & 0.311 & 0.313 & . & 0.287 \\
\hline Chile & . & 0.522 & 0.458 & 0.551 & 0.518 & . & 0.515 \\
\hline Czech Republic & . & 0.208 & 0.140 & 0.166 & . & 0.256 & 0.199 \\
\hline Denmark & 0.128 & 0.203 & . & 0.144 & . & 0.142 & 0.152 \\
\hline Estonia & . & 0.188 & 0.270 & 0.283 & . & 0.275 & 0.256 \\
\hline Finland & . & 0.256 & 0.281 & 0.298 & 0.330 & 0.202 & 0.274 \\
\hline France & 0.175 & 0.530 & . & 0.364 & 0.415 & 0.275 & 0.341 \\
\hline Germany & . & 0.230 & 0.123 & 0.139 & 0.165 & 0.101 & 0.161 \\
\hline Greece & . & . & . & 0.108 & . & 0.245 & 0.186 \\
\hline Hungary & 0.307 & 0.448 & 0.308 & 0.297 & . & 0.416 & 0.360 \\
\hline Iceland & 0.155 & 0.678 & . & 0.174 & . & 0.129 & 0.262 \\
\hline Ireland & 0.333 & 0.352 & . & 0.479 & . & 0.573 & 0.414 \\
\hline Israel & . & . & . & 0.163 & . & . & 0.163 \\
\hline Italy & 0.259 & 0.320 & . & 0.278 & 0.261 & 0.316 & 0.291 \\
\hline Japan & 0.061 & 0.101 & 0.063 & 0.043 & 0.051 & . & 0.062 \\
\hline Korea & 0.129 & 0.181 & 0.144 & 0.132 & 0.105 & . & 0.139 \\
\hline Luxembourg & . & . & 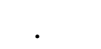 & 0.266 & . & 0.293 & 0.282 \\
\hline Mexico & . & 0.451 & 0.506 & 0.586 & 0.583 & . & 0.529 \\
\hline Netherlands & 0.232 & 0.330 & . & 0.254 & 0.413 & 0.293 & 0.301 \\
\hline New Zealand & . & . & 0.219 & . & 0.241 & . & 0.229 \\
\hline Norway & 0.256 & 0.313 & 0.259 & . & 0.287 & 0.195 & 0.264 \\
\hline Poland & . & 0.420 & 0.487 & 0.346 & 0.486 & 0.316 & 0.406 \\
\hline Portugal & . & 0.494 & . & 0.367 & . & 0.298 & 0.379 \\
\hline Slovakia & . & 0.358 & 0.268 & 0.262 & . & 0.352 & 0.315 \\
\hline Slovenia & . & 0.398 & 0.283 & 0.251 & 0.313 & 0.219 & 0.291 \\
\hline Spain & 0.294 & 0.419 & 0.438 & 0.488 & 0.369 & 0.291 & 0.392 \\
\hline Sweden & 0.133 & 0.249 & 0.159 & 0.122 & 0.162 & 0.163 & 0.159 \\
\hline Switzerland & . & 0.210 & 0.262 & . & 0.206 & 0.147 & 0.206 \\
\hline Turkey & . & 0.314 & 0.318 & 0.401 & 0.452 & . & 0.432 \\
\hline UK & 0.358 & 0.417 & 0.509 & 0.468 & 0.461 & 0.417 & 0.435 \\
\hline USA & 0.275 & 0.379 & 0.368 & 0.323 & 0.287 & . & 0.325 \\
\hline Total & 0.245 & 0.334 & 0.298 & 0.298 & 0.321 & 0.281 & 0.300 \\
\hline
\end{tabular}


Table A10. Mean of instructions-follow by country and wave

\begin{tabular}{|c|c|c|c|c|c|c|c|}
\hline country & 1 & 2 & 3 & 4 & 5 & 6 & Total \\
\hline Australia & . & . & 2.082 & . & . & . & 2.082 \\
\hline Austria & . & 2.020 & . & 1.865 & . & 1.827 & 1.901 \\
\hline Belgium & 2.009 & 1.857 & . & 1.862 & . & 1.925 & 1.895 \\
\hline Canada & 2.222 & 2.239 & . & 2.269 & 2.018 & . & 2.177 \\
\hline Chile & . & 1.923 & 1.980 & 2.243 & . & . & 2.042 \\
\hline Czech Republic & . & 1.666 & 1.996 & 1.966 & . & 1.967 & 1.924 \\
\hline Denmark & 2.368 & 1.817 & . & 2.093 & . & 2.109 & 2.102 \\
\hline Estonia & . & 1.689 & 1.692 & 1.901 & . & 1.941 & 1.820 \\
\hline Finland & . & 1.691 & 1.664 & 1.688 & . & 1.741 & 1.697 \\
\hline France & 1.634 & 1.882 & . & 1.928 & . & 1.872 & 1.837 \\
\hline Germany & . & 2.140 & 1.668 & 2.133 & . & 2.056 & 2.020 \\
\hline Greece & . & . & . & 1.947 & . & 2.047 & 2.004 \\
\hline Hungary & 2.213 & 1.690 & 2.107 & 2.083 & . & 1.999 & 2.025 \\
\hline Iceland & 2.033 & 2.049 & . & 2.097 & . & 1.969 & 2.039 \\
\hline Ireland & 2.196 & 2.057 & . & 2.017 & . & 2.034 & 2.082 \\
\hline Israel & . & . & . & . & . & . & . \\
\hline Italy & 1.803 & 1.817 & . & 1.939 & . & 1.961 & 1.881 \\
\hline Japan & 2.265 & 2.218 & . & 2.195 & . & . & 2.224 \\
\hline Korea & 1.925 & 1.610 & 1.818 & 1.988 & . & . & 1.827 \\
\hline Luxembourg & . & . & . & 1.989 & . & 2.025 & 2.010 \\
\hline Mexico & . & 2.011 & 2.190 & 2.015 & . & . & 2.091 \\
\hline Netherlands & 2.042 & 1.911 & . & 1.971 & . & 1.952 & 1.969 \\
\hline New Zealand & . & . & 2.115 & . & 2.076 & . & 2.098 \\
\hline Norway & 2.303 & 2.276 & 2.270 & . & . & 2.252 & 2.275 \\
\hline Poland & . & 1.618 & . & 1.784 & . & 1.832 & 1.757 \\
\hline Portugal & . & 2.086 & . & 1.968 & . & 1.861 & 1.960 \\
\hline Slovakia & . & 1.634 & 1.996 & 2.019 & . & 2.038 & 1.978 \\
\hline Slovenia & . & 1.615 & 1.572 & 1.709 & . & 1.714 & 1.658 \\
\hline Spain & 1.863 & 1.812 & 1.855 & 1.986 & . & 1.876 & 1.871 \\
\hline Sweden & 2.079 & 2.025 & 2.295 & 2.037 & . & 2.032 & 2.083 \\
\hline Switzerland & . & . & 1.907 & . & . & 1.943 & 1.925 \\
\hline Turkey & . & 2.076 & 2.156 & 1.832 & . & 1.978 & 1.954 \\
\hline UK & 2.130 & 2.014 & . & 2.111 & . & 2.027 & 2.062 \\
\hline USA & 2.420 & 2.389 & 2.352 & 2.440 & . & . & 2.400 \\
\hline Total & 2.101 & 1.947 & 1.998 & 1.994 & 2.035 & 1.959 & 1.990 \\
\hline
\end{tabular}

Table A11. Mean of justify-lying by country and wave

\begin{tabular}{c|ccccc}
\hline country & \multicolumn{1}{|r}{2} & 2 & 4 & 6 & Total \\
\hline & & & & & \\
Australia & & & & & \\
Austria &. & 8.266 & 7.925 & 7.781 & 7.988 \\
Belgium & 7.645 & 7.055 & 7.385 & 7.346 & 7.290 \\
Canada & 8.317 & 8.203 &. &. & 8.251 \\
Chile &. & 8.652 &. &. & 8.652 \\
Czech Republic &. & 7.730 & 8.217 & 7.839 & 7.897 \\
Denmark & 8.864 & 8.913 & 9.016 & 8.963 & 8.939 \\
Estonia &. & 8.416 & 7.988 & 8.526 & 8.343 \\
Finland &. & 8.128 & 8.150 & 8.435 & 8.260 \\
France & 7.488 & 7.258 & 7.326 & 7.878 & 7.507 \\
\hline
\end{tabular}




\begin{tabular}{|c|c|c|c|c|c|}
\hline Germany & . & 7.717 & 7.805 & 8.046 & 7.832 \\
\hline Greece & . & . & 7.896 & 8.540 & 8.268 \\
\hline Hungary & . & 7.297 & 8.496 & 8.270 & 8.056 \\
\hline Iceland & 9.277 & 9.236 & 9.253 & 9.187 & 9.240 \\
\hline Ireland & 8.391 & 8.650 & 8.780 & 8.312 & 8.529 \\
\hline Israel & . & . & . & . & . \\
\hline Italy & 8.920 & 8.258 & 8.587 & 8.815 & 8.605 \\
\hline Japan & . & 8.747 & . & . & 8.747 \\
\hline Korea & . & 8.397 & . & . & 8.397 \\
\hline Luxembourg & . & . & 7.806 & 7.972 & 7.902 \\
\hline Mexico & . & 6.761 & . & . & 6.761 \\
\hline Netherlands & 7.602 & 7.457 & 7.772 & 8.019 & 7.743 \\
\hline New Zealand & . & . & . & . & $\cdot$ \\
\hline Norway & 9.131 & 9.003 & . & 8.699 & 8.949 \\
\hline Poland & . & 8.769 & 8.951 & 7.955 & 8.547 \\
\hline Portugal & . & 7.443 & 8.592 & 8.728 & 8.284 \\
\hline Slovakia & . & 7.695 & 7.794 & 8.061 & 7.849 \\
\hline Slovenia & . & 8.924 & 8.462 & 8.925 & 8.787 \\
\hline Spain & 7.747 & 7.976 & 8.065 & 7.821 & 7.905 \\
\hline Sweden & 8.898 & 8.909 & 8.370 & 7.838 & 8.482 \\
\hline Switzerland & . & 8.358 & . & 8.239 & 8.301 \\
\hline Turkey & . & . & 9.588 & 9.504 & 9.533 \\
\hline UK & 8.070 & 8.222 & 8.028 & 8.614 & 8.268 \\
\hline USA & 8.456 & 8.641 & . & . & 8.537 \\
\hline Total & 8.319 & 8.080 & 8.211 & 8.332 & 8.215 \\
\hline
\end{tabular}

Table A12. Mean of child-unselfish by country and wave.

\begin{tabular}{|c|c|c|c|c|c|c|c|}
\hline country & 1 & 2 & 3 & 4 & 5 & 6 & Total \\
\hline Australia & 0.377 & . & 0.396 & . & 0.536 & . & 0.434 \\
\hline Austria & . & 0.073 & . & 0.054 & . & 0.100 & 0.075 \\
\hline Belgium & 0.144 & 0.272 & . & 0.361 & . & 0.225 & 0.265 \\
\hline Canada & 0.204 & 0.423 & . & 0.456 & 0.464 & . & 0.406 \\
\hline Chile & . & 0.079 & 0.257 & 0.347 & 0.326 & . & 0.238 \\
\hline Czech Republic & . & 0.369 & 0.323 & 0.363 & . & 0.343 & 0.355 \\
\hline Denmark & 0.249 & 0.506 & . & 0.559 & . & 0.634 & 0.494 \\
\hline Estonia & . & 0.249 & 0.168 & 0.164 & . & 0.158 & 0.182 \\
\hline Finland & . & 0.211 & 0.182 & 0.218 & 0.303 & 0.280 & 0.242 \\
\hline France & 0.217 & 0.399 & . & 0.402 & 0.556 & 0.409 & 0.393 \\
\hline Germany & . & 0.080 & 0.054 & 0.087 & 0.069 & 0.051 & 0.070 \\
\hline Greece & . & . & . & 0.257 & . & 0.283 & 0.272 \\
\hline Hungary & 0.140 & 0.258 & 0.288 & 0.230 & . & 0.343 & 0.249 \\
\hline Iceland & 0.209 & 0.752 & . & 0.346 & . & 0.314 & 0.385 \\
\hline Ireland & 0.227 & 0.526 & . & 0.492 & . & 0.512 & 0.421 \\
\hline Israel & . & . & . & 0.490 & . & . & 0.490 \\
\hline Italy & 0.022 & 0.399 & . & 0.414 & 0.439 & 0.408 & 0.345 \\
\hline Japan & 0.281 & 0.440 & 0.378 & 0.532 & 0.503 & . & 0.429 \\
\hline Korea & 0.119 & 0.106 & 0.106 & 0.147 & 0.120 & . & 0.119 \\
\hline Luxembourg & . & . & . & 0.266 & . & 0.323 & 0.298 \\
\hline Mexico & . & 0.110 & 0.365 & 0.487 & 0.476 & . & 0.361 \\
\hline Netherlands & 0.090 & 0.222 & . & 0.279 & 0.235 & 0.227 & 0.208 \\
\hline New Zealand & . & . & 0.328 & . & 0.386 & . & 0.353 \\
\hline
\end{tabular}




\begin{tabular}{c|ccccccc}
\hline Norway & 0.055 & 0.095 & 0.112 &. & 0.198 & 0.174 & 0.125 \\
Poland & $\cdot$ & 0.094 & 0.139 & 0.120 & 0.184 & 0.191 & 0.148 \\
Portugal & $\cdot$ & 0.302 &. & 0.402 &. & 0.389 & 0.365 \\
Slovakia & $\cdot$ & 0.223 & 0.189 & 0.186 &. & 0.264 & 0.218 \\
Slovenia &. & 0.331 & 0.293 & 0.376 & 0.380 & 0.310 & 0.337 \\
Spain & 0.044 & 0.078 & 0.143 & 0.119 & 0.334 & 0.016 & 0.103 \\
Sweden & 0.102 & 0.293 & 0.237 & 0.332 & 0.347 & 0.313 & 0.281 \\
Switzerland & $\cdot$ & 0.391 & 0.326 &. & 0.221 & 0.120 & 0.268 \\
Turkey &. & 0.278 & 0.227 & 0.234 & 0.320 &. & 0.293 \\
UK & 0.406 & 0.566 &. & 0.602 & 0.547 & 0.499 & 0.522 \\
USA & 0.188 & 0.368 & 0.348 & 0.391 & 0.400 &. & 0.321 \\
& & & & & & & \\
\hline Total & 0.175 & 0.266 & 0.247 & 0.311 & 0.346 & 0.292 & 0.279 \\
\hline
\end{tabular}

Table A13. Mean of child-tolerance by country and wave.

\begin{tabular}{|c|c|c|c|c|c|c|c|}
\hline country & 1 & 2 & 3 & 4 & 5 & 6 & Total \\
\hline Australia & 0.671 & . & 0.809 & . & 0.916 & . & 0.805 \\
\hline Austria & . & 0.661 & . & 0.716 & . & 0.687 & 0.689 \\
\hline Belgium & 0.453 & 0.675 & . & 0.846 & . & 0.822 & 0.715 \\
\hline Canada & 0.530 & 0.802 & . & 0.816 & 0.837 & . & 0.768 \\
\hline Chile & . & 0.790 & 0.616 & 0.760 & 0.791 & . & 0.746 \\
\hline Czech Republic & . & 0.661 & 0.600 & 0.632 & . & 0.501 & 0.609 \\
\hline Denmark & 0.584 & 0.809 & . & 0.873 & . & 0.867 & 0.785 \\
\hline Estonia & . & 0.702 & 0.596 & 0.712 & . & 0.768 & 0.702 \\
\hline Finland & . & 0.803 & 0.825 & 0.827 & 0.860 & 0.868 & 0.840 \\
\hline France & 0.589 & 0.783 & . & 0.847 & 0.869 & 0.871 & 0.797 \\
\hline Germany & . & 0.760 & 0.883 & 0.707 & 0.732 & 0.730 & 0.762 \\
\hline Greece & . & . & . & 0.525 & . & 0.536 & 0.531 \\
\hline Hungary & 0.307 & 0.617 & 0.635 & 0.665 & . & 0.708 & 0.572 \\
\hline Iceland & 0.580 & 0.930 & . & 0.843 & . & 0.861 & 0.794 \\
\hline Ireland & 0.560 & 0.764 & . & 0.765 & . & 0.742 & 0.698 \\
\hline Israel & . & . & . & 0.819 & . & . & 0.819 \\
\hline Italy & 0.433 & 0.670 & . & 0.750 & 0.739 & 0.711 & 0.667 \\
\hline Japan & 0.410 & 0.595 & 0.583 & 0.712 & 0.745 & . & 0.611 \\
\hline Korea & 0.249 & 0.554 & 0.468 & 0.647 & 0.560 & . & 0.506 \\
\hline Luxembourg & . & . & . & 0.771 & . & 0.825 & 0.802 \\
\hline Mexico & . & 0.643 & 0.573 & 0.718 & 0.781 & . & 0.667 \\
\hline Netherlands & 0.594 & 0.885 & . & 0.916 & 0.859 & 0.855 & 0.816 \\
\hline New Zealand & . & . & 0.779 & . & 0.825 & . & 0.799 \\
\hline Norway & 0.317 & 0.637 & 0.659 & . & 0.914 & 0.905 & 0.682 \\
\hline Poland & . & 0.765 & 0.815 & 0.791 & 0.843 & 0.739 & 0.788 \\
\hline Portugal & . & 0.678 & . & 0.667 & . & 0.678 & 0.675 \\
\hline Slovakia & . & 0.552 & 0.571 & 0.571 & . & 0.516 & 0.551 \\
\hline Slovenia & . & 0.745 & 0.720 & 0.701 & 0.750 & 0.720 & 0.727 \\
\hline Spain & 0.442 & 0.733 & 0.756 & 0.796 & 0.716 & 0.814 & 0.702 \\
\hline Sweden & 0.711 & 0.908 & 0.904 & 0.923 & 0.936 & 0.916 & 0.891 \\
\hline Switzerland & . & 0.774 & 0.786 & . & 0.907 & 0.856 & 0.830 \\
\hline Turkey & . & 0.691 & 0.613 & 0.623 & 0.692 & . & 0.676 \\
\hline UK & 0.619 & 0.796 & 0.861 & 0.830 & 0.854 & 0.794 & 0.790 \\
\hline USA & 0.524 & 0.726 & 0.749 & 0.798 & 0.790 & . & 0.693 \\
\hline Total & 0.500 & 0.719 & 0.707 & 0.745 & 0.802 & 0.761 & 0.717 \\
\hline
\end{tabular}


Appendix B: Gini coefficients of equivalent net household incomes

\begin{tabular}{|c|c|c|c|c|c|c|c|}
\hline country & 1 & 2 & 3 & 4 & 5 & 6 & Total \\
\hline Australia & 28.10 & . & 30.80 & . & 31.57 & . & 30.32 \\
\hline Austria & $\cdot$ & 25.10 & . & 25.91 & . & 26.67 & 25.90 \\
\hline Belgium & 22.44 & 23.29 & . & 26.82 & . & . & 24.28 \\
\hline Canada & 28.71 & 27.48 & . & 31.50 & 31.55 & . & 30.04 \\
\hline Chile & . & 51.88 & 52.14 & 51.57 & 49.09 & . & 51.26 \\
\hline Czech Republic & . & 21.18 & 25.30 & 25.24 & . & 25.27 & 23.69 \\
\hline Denmark & 27.22 & 25.91 & . & 22.39 & . & 24.98 & 25.18 \\
\hline Estonia & . & 22.48 & 36.17 & 35.86 & . & 31.96 & 31.67 \\
\hline Finland & . & 20.95 & 21.94 & 24.60 & 25.69 & . & 23.59 \\
\hline France & 28.80 & 27.12 & . & 26.75 & 27.94 & 28.00 & 27.68 \\
\hline Germany & . & 26.55 & 26.28 & 26.51 & 28.53 & 29.96 & 27.45 \\
\hline Greece & . & . & . & 33.56 & . & 33.53 & 33.54 \\
\hline Hungary & 22.08 & 32.30 & 28.85 & 29.20 & . & 27.67 & 27.45 \\
\hline Iceland & . & . & . & . & . & 28.63 & 28.63 \\
\hline Ireland & 33.30 & 33.01 & . & 32.15 & . & 30.66 & 32.34 \\
\hline Israel & . & . & . & 34.60 & . & . & 34.60 \\
\hline Italy & 30.61 & 30.66 & . & 33.71 & 33.99 & . & 32.14 \\
\hline Japan & 25.20 & 28.03 & 29.08 & 32.82 & 35.88 & . & 30.27 \\
\hline South Korea & 36.07 & 31.97 & 29.01 & 32.25 & 31.84 & . & 32.05 \\
\hline Luxembourg & . & . & . & 26.35 & . & 28.42 & 27.53 \\
\hline Mexico & . & 47.24 & 47.70 & 49.10 & 46.05 & . & 47.54 \\
\hline Netherlands & 25.75 & 26.21 & . & 23.10 & 27.36 & 27.82 & 26.21 \\
\hline New Zealand & $\cdot$ & $\cdot$ & 36.40 & . & 32.92 & . & 34.87 \\
\hline Norway & 22.17 & 23.25 & 23.47 & $\cdot$ & 24.08 & 24.08 & 23.40 \\
\hline Poland & . & 25.74 & 30.76 & 28.90 & 31.29 & 29.67 & 28.84 \\
\hline Portugal & . & 31.01 & . & 35.43 & . & 35.90 & 34.22 \\
\hline Slovakia & . & 17.64 & 23.76 & 23.71 & . & 22.99 & 21.77 \\
\hline Slovenia & . & 21.79 & 24.43 & 24.90 & 24.50 & 25.37 & 24.26 \\
\hline Spain & 31.12 & 30.30 & 35.30 & 33.65 & 31.44 & 31.28 & 31.78 \\
\hline Sweden & 20.13 & 20.70 & 21.73 & 23.33 & 23.52 & . & 22.14 \\
\hline Switzerland & . & 30.91 & 28.73 & . & . & . & 29.89 \\
\hline Turkey & . & 43.68 & 43.41 & 43.54 & . & . & 43.53 \\
\hline United Kingdom & 26.96 & 32.77 & 34.29 & 34.70 & 34.96 & . & 32.61 \\
\hline USA & 30.36 & 33.53 & 36.26 & 37.04 & 36.87 & . & 34.17 \\
\hline Total & 27.79 & 28.82 & 32.68 & 32.11 & 32.23 & 28.55 & 30.42 \\
\hline
\end{tabular}




\section{Appendix C: Control variables}

Due to different coding, the EVS 2008 wave had to be harmonized with the already harmonized 1980-2005 WVS data. The descriptive statistics of all control variables are summarized in Table C1.

Respondents' age is directly taken from the harmonized WVS data, but is calculated using the birth year for the EVS 2008. In the WVS data, income is coded in ten categories with different category boundaries for each country. In contrast, the EVS 2008 provides twelve income categories with the same categories for all countries. Income is harmonized by approximating income quintiles in each data set. The third quintile is used as reference category. The legal status is coded in four dummies, indicating single, married, divorced or widowed, with single being the reference category. To control for labor market status, eight dummies are used, capturing full and part time employment, self-employment, being retired, student, housewife, unemployed or other; full employment is used as the reference category. Religiosity is captured by dummies for the frequency of attendance to religious services. Town size is captured by eight dummies, and towns with less than 2,000 inhabitants is the reference category.

Table C1. Summary statistics of micro control variables

\begin{tabular}{c|ccccc}
\hline Variable & Obs & Mean & Std. Dev. & Min & Max \\
\hline female & & & & & \\
age & 196296 & 0.529 & 0.499 & 0 & 1 \\
age_sqr & 192281 & 44.379 & 17.321 & 14 & 108 \\
edu_no & 192281 & 2269.536 & 1674.580 & 196 & 11664 \\
edu_prime & 131700 & 0.061 & 0.240 & 0 & 1 \\
edu_somesec & 131700 & 0.242 & 0.428 & 0 & 1 \\
edu_sec & 131700 & 0.230 & 0.421 & 0 & 1 \\
edu_uni & 131700 & 0.303 & 0.459 & 0 & 1 \\
& 131700 & 0.161 & 0.368 & 0 & 1 \\
inc_quint1 & 170456 & 0.186 & 0.389 & 0 & 1 \\
inc_quint2 & 170456 & 0.272 & 0.445 & 0 & 1 \\
inc_quint3 & 170456 & 0.229 & 0.420 & 0 & 1 \\
inc_quint4 & 170456 & 0.168 & 0.374 & 0 & 1 \\
inc_quint5 & 170456 & 0.145 & 0.352 & 0 & 1 \\
stat_single & 194392 & 0.232 & 0.422 & 0 & 1 \\
stat_married & 194392 & 0.623 & 0.485 & 0 & 1 \\
stat_divorced & 194392 & 0.068 & 0.252 & 0 & 1 \\
stat_widowed & 194392 & 0.076 & 0.264 & 0 & 1 \\
jobstat_full & 190515 & 0.413 & 0.492 & 0 & 0 \\
jobstat_part & 190515 & 0.076 & 0.265 & 0 & 1 \\
\hline
\end{tabular}




\begin{tabular}{c|lllll}
\hline jobstat_self & 190515 & 0.067 & 0.250 & 0 & 1 \\
jobstat_retired & 190515 & 0.186 & 0.389 & 0 & 1 \\
jobstat_wife & 190515 & 0.124 & 0.330 & 0 & 1 \\
jobstat_student & 190515 & 0.059 & 0.236 & 0 & 1 \\
jobstat_unemp & 190515 & 0.056 & 0.230 & 0 & 1 \\
jobstat_other & 190515 & 0.019 & 0.136 & 0 & 1 \\
& & & & & 1 \\
religion_none & 188182 & 0.403 & 0.491 & 0 & 1 \\
religion_some & 188182 & 0.271 & 0.444 & 0 & 1 \\
religion_reg & 188182 & 0.326 & 0.469 & 0 & 1 \\
& & & & & 1 \\
townsize_1 & 137667 & 0.176 & 0.381 & 0 & 1 \\
townsize_2 & 137667 & 0.098 & 0.297 & 0 & 1 \\
townsize_3 & 137667 & 0.090 & 0.286 & 0 & 1 \\
townsize_4 & 137667 & 0.101 & 0.302 & 0 & 1 \\
townsize_5 & 137667 & 0.131 & 0.337 & 0 & 1 \\
townsize_6 & 137667 & 0.099 & 0.298 & 0 & 1 \\
townsize_7 & 137667 & 0.157 & 0.364 & 0 & 0 \\
townsize_8 & 137667 & 0.143 & 0.350 & & \\
\hline
\end{tabular}

Macroeconomic control variables stem from both the OECD and the World Bank datasets, as displayed in Table C2. The results reported in this paper are based on OECD data.

Table C2. Summary statistics of macro control variables

\begin{tabular}{|c|c|c|c|c|c|}
\hline Variable & Obs & Mean & Std. Dev. & Min & $\operatorname{Max}$ \\
\hline ln_pcgdp_oecd & 190259 & 9.90 & 0.44 & 8.52 & 11.08 \\
\hline ln_pcgdp_wdi & 195360 & 10.00 & 0.45 & 8.72 & 11.20 \\
\hline unemp_oecd & 180103 & 7.39 & 3.88 & 0.46 & 22.96 \\
\hline unemp_wdi & 163559 & 7.46 & 3.78 & 0.60 & 22.70 \\
\hline gdp_growth_oecd & 176361 & 2.48 & 3.16 & -11.61 & 10.65 \\
\hline gdp_growth_wdi & 193454 & 1.82 & 3.95 & -14.57 & 10.65 \\
\hline
\end{tabular}

